\title{
Optimal Management of the Critically Ill: Anaesthesia, Monitoring, Data Capture, and Point-of-Care Technological Practices in Ovine Models of Critical Care
}

\author{
Saul Chemonges, ${ }^{1,2,3}$ Kiran Shekar, ${ }^{1,2,4}$ John-Paul Tung, ${ }^{1,5}$ \\ Kimble R. Dunster, ${ }^{1,6}$ Sara Diab, ${ }^{1,2}$ David Platts, ${ }^{1,2}$ Ryan P. Watts, ${ }^{1,7}$ \\ Shaun D. Gregory, ${ }^{1,2,8}$ Samuel Foley, ${ }^{1,2}$ Gabriela Simonova, ${ }^{1,2}$ Charles McDonald,, \\ Rylan Hayes, ${ }^{1,2}$ Judith Bellpart, ${ }^{1,2}$ Daniel Timms, ${ }^{1,8}$ Michelle Chew, ${ }^{1}$ Yoke L. Fung, ${ }^{1,2}$ \\ Michael Toon, ${ }^{1}$ Marc O. Maybauer, ${ }^{1,2}$ and John F. Fraser ${ }^{1,2,8}$ \\ ${ }^{1}$ Critical Care Research Group Laboratory, The Prince Charles Hospital, Rode Road, Chermside, Brisbane, QLD 4032, Australia \\ ${ }^{2}$ The University of Queensland, St Lucia, Brisbane, QLD 4072, Australia \\ ${ }^{3}$ Medical Engineering Research Facility (MERF), Queensland University of Technology, Brisbane, QLD 4001, Australia \\ ${ }^{4}$ Bond University, Gold Coast, QLD 4226, Australia \\ ${ }^{5}$ Research and Development, Australian Red Cross Blood Service, Kelvin Grove, Brisbane, QLD 4059, Australia \\ ${ }^{6}$ Science and Engineering Faculty, Queensland University of Technology, Brisbane, QLD 4001, Australia \\ ${ }^{7}$ Department of Emergency Medicine, Princess Alexandra Hospital, 199 Ipswich Road, Woolloongabba, QLD 4102, Australia \\ ${ }^{8}$ Innovative Cardiovascular Engineering and Technology Laboratory, The Prince Charles Hospital, Chermside, Brisbane, \\ QLD 4032, Australia
}

Correspondence should be addressed to Saul Chemonges; saul.chemonges@qut.edu.au

Received 13 September 2013; Revised 21 January 2014; Accepted 10 February 2014; Published 25 March 2014

Academic Editor: Izumi Takeyoshi

Copyright (C) 2014 Saul Chemonges et al. This is an open access article distributed under the Creative Commons Attribution License, which permits unrestricted use, distribution, and reproduction in any medium, provided the original work is properly cited.

Animal models of critical illness are vital in biomedical research. They provide possibilities for the investigation of pathophysiological processes that may not otherwise be possible in humans. In order to be clinically applicable, the model should simulate the critical care situation realistically, including anaesthesia, monitoring, sampling, utilising appropriate personnel skill mix, and therapeutic interventions. There are limited data documenting the constitution of ideal technologically advanced large animal critical care practices and all the processes of the animal model. In this paper, we describe the procedure of animal preparation, anaesthesia induction and maintenance, physiologic monitoring, data capture, point-of-care technology, and animal aftercare that has been successfully used to study several novel ovine models of critical illness. The relevant investigations are on respiratory failure due to smoke inhalation, transfusion related acute lung injury, endotoxin-induced proteogenomic alterations, haemorrhagic shock, septic shock, brain death, cerebral microcirculation, and artificial heart studies. We have demonstrated the functionality of monitoring practices during anaesthesia required to provide a platform for undertaking systematic investigations in complex ovine models of critical illness.

\section{Introduction}

Optimal management of the critically ill is the goal for ongoing research utilising clinically relevant animal models. The body size and close similarities between sheep and human pulmonary anatomy, physiology, and immunology make sheep a suitable species for studying pathologies afflicting humans [1-3]. In comparison, swine also offer considerable advantages over other large animal models in biomedical research for the same or more reasons as sheep and ease of management [4-6]. Anaesthesia is a requirement during interventions in animal research to minimise or eliminate 
the experimental induction of pain. Optimal anaesthesia and analgesia need to be titrated to the individual animal under close monitoring and supervision aided by the use of patient monitors, data capturing devices, and patient pointof-care technology. Patient monitors are designed to aid in determining priorities for care and are not meant to replace the clinician [7-9] at the tableside. They provide an avenue for recording significant events to enhance the recognition of trends in important physiological variables [9-12]. Complex experiments using ovine models therefore necessitate access to a well-equipped theatre with advanced organ system monitoring and point-of-care technology that allows realtime tailoring of therapy and standardisation of anaesthesia and critical care practices. Additionally, appropriately trained researchers with a thorough understanding of the use and interpretation of these systems and of ovine physiology are essential.

Currently, there are varied methodologies of ovine anaesthesia, monitoring, organ support, and point-of-care devices in use in large animal intensive care units (ICUs) and research facilities around the world. To date, however, there are limited studies that describe in detail sheep anaesthesia and monitoring practices in biomedical research establishments with modern large animal ICUs. The aim of this paper is to provide an overview of anaesthesia and monitoring practices used in sheep in comparison with a detailed description of the procedure of animal preparation, anaesthesia and monitoring, critical care, data capture, and point-of-care technology developed by our research group on several validated ovine models (Table 1). It is expected that this paper will provide a foundation for comparison of the available ICU monitoring technology for large animal experimental models and will set an example of recognising the available anaesthetics and standards of devices currently marketed for use in large animal models of intensive care.

\section{Overview of Anaesthesia and Monitoring Practices for Ovine Models}

Reports from the past ten years show that there were considerable variations in anaesthesia and monitoring practices in sheep utilised in biomedical research [2, 17, 29-76]. Ketamine was the most commonly used induction agent followed by thiopentone. Only a few studies used alfaxalone for induction of anaesthesia [2, 17, 31, 76]. For maintenance of anaesthesia, halothane in $\mathrm{O}_{2}$ was the most commonly used agent followed by isoflurane in $\mathrm{O}_{2}$. A limited number of studies used alfaxalone for maintenance of anaesthesia $[2,17,76]$. Female sheep of the Merino breed were used in most of the experiments probably because of their docile nature and relative availability compared to males. While it is difficult to parse out the rationale for the various alternative approaches for ovine anaesthesia and monitoring in many published studies, the experimental goal, at least in part, impacts the procedure to be implemented. Several studies required anaesthesia only during instrumentation, as subsequent experimental procedures required sheep to be conscious. In sheep that required assisted ventilation, the Servo ventilator (model 900C, Siemens-Elena; Solna, Sweden) was the most commonly used device. In studies that documented the method of euthanasia of sheep, the administration of ketamine anaesthesia in combination with a saturated potassium chloride solution was the most commonly used approach. Unlike companion and other laboratory animal anaesthesia, small ruminant anaesthesia is an area that is still evolving, which may explain the variability in anaesthesia and monitoring techniques. Furthermore, sheep are not routinely anaesthetised in veterinary practice; therefore, few anaesthetics or procedures have been developed specifically for this species. For this reason and probably because they are food animals, many anaesthetic drugs are not registered for use in sheep. Several other factors that may affect the choice of anaesthesia and monitoring include experience with the species, anaesthetic drug costs and availability, and monitoring facilities.

There is also considerable diversity in the types of technological devices used for physiological monitoring during anaesthesia and equipment used in point-of-care in various centres that have studied sheep. Some differences of these devices are notably in the type of physiological monitors, blood gas analysers, pressure transducers, anaesthetic gas analysers, blood flow meters, data acquisition recorders, oximeters, cardiac output monitors, brain monitors, blood cell counters, protein assayers, and colloid osmometers (Table 2).

A consideration of all the factors on anaesthetics and monitoring technology is very helpful for aiding future investigators in making the appropriate choices for the sort of gear required for procedures they would like to implement in their large animal studies.

\section{Laboratory Practices for Ovine Models at the Critical Care Research Group (CCRG) in Australia}

In this section, we describe anaesthesia, critical care and monitoring practices, data capture, and point-of-care technological techniques used at a large Australian animal research laboratory. The CCRG Laboratory has considerable experience in anaesthetising sheep under ICU conditions and has developed several validated ovine models. The areas of discussion are classified into anaesthesia practice, advanced monitoring, auxiliary life support equipment, and point-ofcare technology. Brief overviews of the relevant ovine models are also provided.

3.1. Animal Care, Anaesthesia, and Monitoring. Animals are treated in accordance with the Australian Code of Practice for the Care and Use of Animals for Scientific Purposes [77]. All studies are registered with institutional Animal Welfare and Ethics departments and have the Animal Ethics Committee (AEC) approval from The Queensland University of Technology (QUT) and The University of Queensland (UQ). Local guidelines mandate the presence of at least two trained personnel to be with the animal model at all times for the duration of a given experiment. This is 
TABLE 1: Validated ovine models of the Critical Care Research Group (CCRG) in Australia.

\begin{tabular}{|c|c|c|}
\hline Model & Total number of sheep required & Publications \\
\hline Extracorporeal membrane oxygenation (ECMO) & 72 & {$[2,13-16]$} \\
\hline Transfusion-related acute lung injury (TRALI) & 112 & [17-20] \\
\hline Cardiac mechanical assist device project (CMADP) & $9+$ (ongoing study) & [21-24] \\
\hline Colloids, red cells, aged red cells, sepsis, and haemorrhage (CRASH-S and CRASH-H) & $16+($ ongoing study) & {$[20]$} \\
\hline Smoke induced acute lung injury (S-ALI) & 20 & {$[25]$} \\
\hline Brain stem death (BSD) & 24 & {$[26,27]$} \\
\hline Intracardiac echocardiography guided transseptal catheterization (ICETSC) & $20+$ (ongoing study) & {$[28]$} \\
\hline
\end{tabular}

TABLE 2: Technological devices used in anaesthesia and critical care monitoring in biomedical research on ovine models.

\begin{tabular}{|c|c|}
\hline Devices & Models \\
\hline Physiological monitors & $\begin{array}{l}\text { Mindray } 9200 \text { anaesthetic monitor (Mindray, Shenzhen, China) [31]; multichannel Gould polygraph } \\
\text { recorder (Gould, Valley View, OH, USA) [46]; SurgiVet monitor (SurgiVet V9203; Smiths Medical, MA, } \\
\text { USA) [30]; Datex monitor (Datex-Engstrom Compact; Datex-Engstrom Inc., Tewksbury, MA, USA) [50]; } \\
\text { System 6, (Triton Technology SD, CA, USA) [52]; haemodynamic monitor (MP150, BIOPAC Systems, } \\
\text { Goleta, CA, USA) [36]; 7830A (Hewlett Packard, Santa Clara, CA, USA) } \\
\text { [35, 41, 44, 45, 54, 56, 65-67, 72-74, 79]; V24C (Philips Medizin Systeme Böblingen, Böblingen, Germany) } \\
\text { [53]; IntelliVue MP50 (Philips Medical Systems, Böblingen, Germany) [49]; V24 and V26 (Philips-Agilent, } \\
\text { Andover, MA, USA) [68]; and OM9 (Electronics for Medicine, Pleasantville, NY, USA) [40, 53, 68, 75]. }\end{array}$ \\
\hline Blood gas analysers & $\begin{array}{l}\text { iSTAT CG4 (Abbott Laboratories, USA) [31]; Radiometer ABL } 700 \text { (Radiometer America Inc., OH, USA) } \\
\text { [30]; ABL 700, (Radiometer, Copenhagen, Denmark) [42]; ABL } 5 \text { (Radiometer, Copenhagen, Denmark) } \\
\text { [69]; ABL 500 (Radiometer, Westlake, OH, USA) [64]; ABL } 800 \text { Flex (Radiometer, Copenhagen, } \\
\text { Denmark) [37]; IL GEM Premier } 3000 \text { (IL GEM, GMI, MN, USA) [33, 43, 48]; } 1302 \text { IL (Instrumental } \\
\text { Laboratory, Lexington, MA, USA) [38, 68]; IL1600 (Instrumentation Laboratory, Lexington, MA, USA) } \\
\text { [39]; and Synthesis } 15 \text { (Instrumentation Laboratories, Lexington, MA, USA) } \\
\text { [35, 41, 44, 45, 54, 56, 65-67, 72-74, 79]. }\end{array}$ \\
\hline
\end{tabular}

Statham pressure transducer (Statham, Oxnard, CA, USA) [46]; pressure transducers (Edwards Lifesciences LLC, Irvine, CA, USA) [40, 53, 68, 75]; pressure transducer (ITL Healthcare, Australia) [30]; pressure transducer (Medex Medical Ltd., Lancs, UK) [50]; pressure transducer (Vigilance, Edwards Pressure transducers $\quad$ Lifesciences, S.A., Saint-Prex, Switzerland) [50]; pressure transducer PT (COBE, Argon, TX, USA) [69]; PX3X3 (Baxter, Edwards Critical Care Division, Irvine, CA, USA)

[35, 41, 44, 45, 53, 54, 56, 65, 66, 73, 74, 79]; PX-1800 (Baxter, Edwards Critical Care Division, Irvine, CA, USA) [67, 72]; and PXMK 1590 (Edwards Lifesciences) [49].

Anaesthetic gas analyser (Datex Capnomac; Datex-Ohmeda, Madison, WI, USA) [46]; Capnomac Anaesthetic gas analysers $\quad$ (Ultima, Datex-Ohmeda, Helsinki, Finland) [61]; lactate + NO (YSI 2300, OH, USA); nitric oxide monitor (Micro Medical, ME, USA) [64, 72]; and GEM Premier 3000 (Instrumentation Laboratory, Lexington, MA, USA) [49]. \begin{tabular}{ll}
\hline Blood flow meters & Triton System 6 (model 200, Triton Technology, San Diego, CA, USA) [57, 58]; FBF monitor (model \\
T201/T206, Transonic Systems, Ithaca, NY, USA) [69]; and T208 Transonic Volume Flow Meter
\end{tabular} (Transonic Systems, Ithaca, NY, USA) [53, 68].

PowerLab/8SP (ADInstruments, Castle Hill, Australia) [57, 58]; Data Acquisition System (Cornell

Data acquisition and recorders University, Ithaca, NY); electronic analog-to-digital converter (NIDAQ, National Instruments, Austin, TX, USA) [69]; and Chart 5 acquisition software (ADInstruments, Sydney, Australia) [60].

OSM3 Haemoximeter, (Radiometer, Westlake, OH, USA) [64]; Haemoximeter (OSM2, Radiometer) [69];

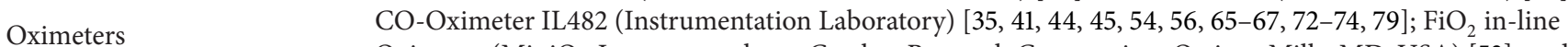
Oximeter (MiniOx I oxygen analyser, Catalyst Research Corporation, Owings Mills, MD, USA) [53]; and CO-Oximeter 682 (Instrumentation Laboratory, Lexington, MA, USA) [68].

Vigilance CCO monitor (Edwards Lifesciences, CA, USA) [36, 37]; capnodynamic CO measurement using Fleisch pneumotachograph (Hans Rudolph Inc., Kansas City, MO, USA) [61]; COM-1

Cardiac output monitors (Baxter-Edwards Critical Care Division, Irvine, CA, USA) [35, 41, 44, 45, 54, 56, 65-67, 72-74, 79]; Monitor 9530 (Baxter-Edwards Critical Care, CA, USA) [53]; and 9520A Cardiac Output Computer (American Edwards Laboratories, Irvine, CA, USA) [40, 53, 68, 75].

Brain monitors $\quad$ EEG (A1000, Aspect Medical Systems, Yatic, MA, USA) [55].

Blood cell counters $\quad$ WBC (Hemavet, HV950FS, Drew Scientific, Inc., TX, USA) [33, 48].

Protein assay TP assay refractometer (National Instrument, Baltimore, MD, USA) [39, 75].

Colloid osmometers 4100 (Wescor, Logan, UT, USA) and 4420 (Wescor, Logan, UT, USA) [49]. 
necessary not only for animal welfare purposes but also for the proactive minimisation of staff fatigue. A team of scientists, nurses, veterinarians, intensive care specialists, surgeons, cardiologists, and perfusionists are present during commencement of complex experiments and remain on call for the duration of the experiment. If at any time the animal becomes physiologically distressed to such an extent that it cannot be managed or reversed, it will be immediately euthanized and documented accordingly.

\subsubsection{Animal Selection and Preanaesthetic Care. Batches of} healthy adult sheep (Ovis aries) are procured from a breeding institution and reared as a flock in an open pasture farm. Sheep sizes are tailored to specific experiments and their weights are generally in the range of that of a small adult human [78]. Within two weeks prior to experiments, animals are transported to and housed at a purpose built animal facility and managed as per standard operating procedures. The sheep are fed with proprietary sheep feed and lucerne and have free access to water. Shelter is provided in built sheds in which the sheep have to free access. Shade is provided by large trees in the paddocks and the sheep interact freely with each other. In general, animals are fasted overnight with free access to drinking water until two hours before the procedure. The sheep are subjected to preexperimental complete veterinary clinical examination which includes body temperature, pulse, and respiratory (TPR) parameter checks. The sheep are then restrained in a sling cage and the ventral aspect of the neck is shaved to facilitate vascular access.

3.1.2. Anaesthesia Technique. Each study has a different protocol of maintenance drugs for total intravenous anaesthesia (TIVA), but the initial induction and instrumentation for haemodynamic monitoring is essentially identical across all the studies. The BSD studies form the foundation of this technique [27]. Under local anaesthesia with lignocaine $1 \%$, a 7FG triple-lumen central venous line (ArrowHowes, Research Triangle Park, NC, USA) is placed in the external jugular vein (EJV) of the awake sheep. The internal jugular vein (IJV) is usually of small calibre and is often absent in sheep [80]. This catheter is used for initial blood sampling and for intravenous (IV) administration of premedication, induction agents, drugs, fluids, and TIVA throughout the procedure. Following any required baseline blood sampling, the sheep are administered buprenorphine $(0.01 \mathrm{mg} / \mathrm{kg})$ by slow IV injection to minimise distress during subsequent procedures. For experiments requiring prolonged cannulation procedures, further sedation with midazolam is indicated. An 8Fr sheath is placed in the left EJV under local anaesthesia for subsequent placement of a pulmonary artery catheter (Edwards Lifesciences, Irvine, CA, USA). Additional sheaths may be placed in the opposite EJV to facilitate cannulation and intracardiac echocardiography (ICE) in ovine extracorporeal membrane oxygenation (ECMO) experiments (Figure 1). General anaesthesia is induced by intravenous administration of midazolam $(0.5 \mathrm{mg} / \mathrm{kg})$ and alfaxalone $(3 \mathrm{mg} / \mathrm{kg}$ ) (Alfaxan Anaesthetic Injection, Jurox Pty Ltd., NSW, Australia). Alfaxalone is given in 4 aliquots

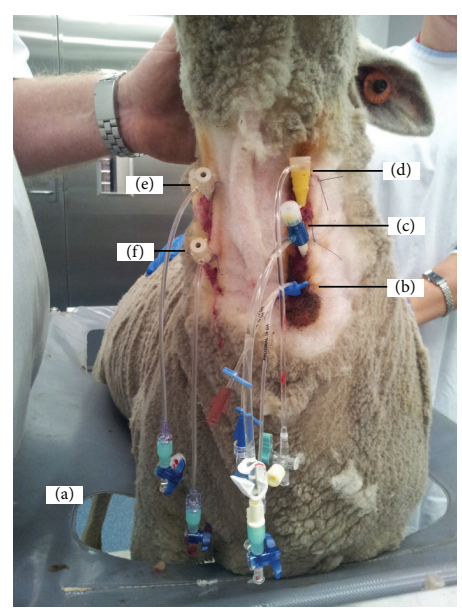

Figure 1: An adult Merino ewe being prepared for venovenous extracorporeal membrane oxygenation (VV-ECMO). VV-ECMO is implemented in patients with severe respiratory failure refractory to conventional ventilatory support to provide gas exchange. Venous blood from the patient is accessed from large central veins and returned to the right atrium after it has passed through an oxygenator. The animal has been restrained in a sling cage (a); ventral neck hair has been clipped and aseptically prepared to allow intravenous access to be gained; note the brown colour of povidone iodine. A multilumen central venous catheter has been inserted into the left jugular vein of the animal under local anaesthetic and sutured into place (b) to allow for blood sampling and medications and fluid administration. The left jugular vein has been further cannulated with an $8 \mathrm{G}$ sheath for the insertion of a pulmonary artery catheter (c) for haemodynamic monitoring. An $11 \mathrm{G}$ sheath catheter has been inserted proximally into the left jugular vein under local anaesthetic and sutured into place to allow for intracardiac echocardiography (ICE) catheter to be inserted (d). The right jugular vein has been cannulated both proximally (e) and distally (f) with single lumen central lines to aid subsequent insertion of return and access ECMO cannulae, respectively. Incremental doses of midazolam are administered to maintain sheep comfort during the prolonged procedure.

at $15 \mathrm{~s}$ intervals. Anaesthesia is maintained with continuous infusions of alfaxalone $(4-6 \mathrm{mg} / \mathrm{kg} / \mathrm{hr}$ ), ketamine (3$5 \mathrm{mg} / \mathrm{kg} / \mathrm{hr}$ ), and midazolam (0.25-0.5 mg/kg/hr). Buprenorphine $0.01 \mathrm{mg} / \mathrm{kg}$ is administered intravenously every six hours throughout the study period for ongoing analgesia. Anaesthetic drug doses are titrated to maintain an appropriate plane of anaesthesia determined by monitoring heart rate, blood pressure, respiratory rate, eyelash reflexes, chewing, jaw movements, and haemodynamics [81-84]. Gentamicin $240 \mathrm{mg}$ and cephalothin $1 \mathrm{~g}$ are administered intravenously for presurgical prophylaxis in lengthy experiments such $24 \mathrm{~h}$ ECMO studies.

Alfaxalone is currently only approved for use in cats and dogs [85-88]. Animal models such as those that are being developed for investigation of critical illness result in significant physiological insult to the experimental subject. Hypoxia, acidosis, and haemodynamic instability are common sequelae of the experimental pathological states under investigation. Consequently, the choice of the anaesthetic 
agent is guided by effective anaesthesia and analgesia and appropriate surgical conditions. Haemodynamic stability is an essential consideration. Agents such as inhaled anaesthetics or propofol often cause hypotension, which could interfere with the effect of the insult under investigation. Alfaxalone provides consistent anaesthetic conditions with good haemodynamic stability [89]. It however continues to be considerably expensive, leading to significant limitations for its use in large animals. Addition of ketamine and midazolam provides analgesia as well as reducing the requirement of alfaxalone as a single agent for anaesthesia. To our knowledge, it is only our studies that have used and continue to use alfaxalone for induction and maintenance of anaesthesia in a large number of sheep. We have been very successful with the combination of alfaxalone, ketamine, midazolam, and buprenorphine with or without fentanyl for the maintenance of anaesthesia and analgesia. This approach continues to be the mainstay for TIVA in our experiments with consistent and desirable anaesthetic outcomes.

3.1.3. Airway Access and Ventilation. The sheep are intubated whilst in the sling cage with assistance from animal handlers. Orotracheal intubation is performed with size 8,9 , or 10 cuffed endotracheal tube, depending on sheep size (Portex; Smiths Medical, Australia) under direct laryngoscopy and ventilation with $100 \%$ oxygen via an ambu bag. Sheep are then placed on the surgical table (or into a metabolic cage depending on the study) in lateral recumbent position for further instrumentation. Mechanical ventilation is commenced using a Galileo intensive care ventilator (Hamilton Medical AG, Switzerland) with a sidestream end-tidal $\mathrm{CO}_{2}\left(\mathrm{ETCO}_{2}\right)$ detector (Marquette TRAM, GE Healthcare, Waukesha, WI, USA). The initial ventilator tidal volume is set to approximately $10 \mathrm{~mL} / \mathrm{kg}$ with a respiratory rate of 15 breaths/min, positive end expiratory pressure (PEEP) of $5 \mathrm{~cm} \mathrm{H}_{2} \mathrm{O}$, and initial $\mathrm{FiO}_{2}$ (fraction of inspired oxygen) of 1.0. These settings are then titrated based on arterial blood gas $(A B G)$ results. In studies involving models of acute lung injury, a low tidal volume, high PEEP strategy is employed to minimise ventilator induced lung injury [9092]. In the majority of studies, a tracheostomy is performed to facilitate bronchoalveolar sampling. This is necessary as standard bronchoscopes are not of sufficient length to access segmental bronchi in sheep through an endotracheal tube. An appropriately sized tracheostomy tube (average size 7-10) (Portex, Smiths Medical, Australia) is inserted surgically into the trachea via a $3 \mathrm{~cm}$ transverse incision made between two tracheal rings at approximately 6 tracheal rings distal to the cricoid cartilage. After securing the airway, the orotracheal tube is then withdrawn and animals are ventilated through the tracheostomy tube. An orogastric tube is inserted and the distal end is sutured to the lower lip and allowed free drainage or suction to prevent ruminal tympany.

3.1.4. Haemodynamic Monitoring. Detailed reviews of principles and practices of haemodynamic monitoring and management are beyond the scope of this paper; readers are referred elsewhere [93-98]. The transfacial artery is surgically exposed and cannulated for invasive blood pressure monitoring and for ABG sampling. Physiologic variables are continually monitored with the Marquette Solar 8000 Patient ICU CCU Monitoring System (GE Healthcare, Waukesha, WI, USA) and recorded every five seconds with custom software. A pulmonary artery catheter (Swan-Ganz CCOmbo, Edwards Lifesciences, Irvine, CA, USA) is inserted via the EJV sheath and is coupled with the Vigilance II monitor (Edwards Lifesciences, Irvine, CA, USA) to record continuous cardiac output (CCO), mixed venous oxygen saturation $\left(\mathrm{SvO}_{2}\right)$, central venous pressure (CVP), pulmonary artery pressure (PAP), systemic vascular resistance (SVR), stroke volume (SV), and core body temperature (BT). Indices can be corrected for body surface area (BSA) using the following equation: BSA $\left(\mathrm{m}^{2}\right)=0.094$ (body weight in $\left.\mathrm{kg}\right)^{0.67}$ [99]. Measured variables are recorded every five seconds using proprietary software. CVP and PAP measurements are taken from the respective ports of the Swan-Ganz CCOmbo catheter. Pulmonary artery occlusion pressure (PAOP) can also be measured when required. Direct arterial blood pressure $(A B P)$ measurements are taken from the facial artery and transduced to the Marquette Solar 8000 monitor. Electrocardiography (ECG) readings are achieved via an ECG module and routed to the monitor. The accuracy of any devices such as those used to measure blood pressure is an important consideration when selecting monitoring equipment for use in animals [100]. We routinely measure and monitor direct ABP and CVP. Monitoring of CVP is useful in measurement of hydrostatic pressure in the intrathoracic vena cava which is a useful guide not only in fluid replacement therapy but also to the ability of the right heart to handle the venous return [9]. Direct blood pressure measurement is not without problems; clotting in the catheter can occur; time is required to instrument the patient; the electronic equipment is expensive; and potentially fatal complications can occur [101].

The laboratory is also equipped with an ultrasonic cardiac output monitor (USCOM A1, Sydney, NSW, Australia). This device is used to guide haemodynamic management and to collect additional haemodynamic data $[102,103]$. Depending on the experiment, transthoracic, epicardiac, or intracardiac echocardiography may be used in our models for cardiac function assessment and data collection purposes.

3.1.5. Respiratory Monitoring. Continuous pulse oximetry $\left(\mathrm{SPO}_{2}\right)$ and $\mathrm{ETCO}_{2}$ recordings are achieved via couplings to the Marquette Solar 8000 monitor. Pulse oximetry provides a measure of oxyhaemoglobin saturation in blood and is one of the most utilised monitoring aids in the critically ill or emergent patient [7, 9, 10, 104]. Accuracy and failure rates (failure to produce a reading) vary widely from model to model and from species to species [105]. We obtain reasonably accurate $\mathrm{ETCO}_{2}$ measurements that provide valuable information on the ventilatory status of the patient $[9-11,104,106] . \mathrm{ETCO}_{2}$ measurement also provides an early warning of serious hypotension and very low cardiac output from the right side of the heart and detects apnoea and breathing circuit 
disconnections $[10,106]$. Arterial blood samples are collected from the facial artery at predetermined intervals depending on the study. ABGs are determined using an automated analyser (ABL800 Flex Radiometer, Copenhagen, Denmark), providing readings for arterial partial pressures of $\mathrm{O}_{2}\left(\mathrm{P}_{\mathrm{a}} \mathrm{O}_{2}\right)$ and carbon dioxide $\left(\mathrm{P}_{\mathrm{a}} \mathrm{CO}_{2}\right)$. The $\mathrm{ABG}$ analyser also provides absolute values for oximetry including the concentrations of total blood haemoglobin (ctHb), oxygen saturation $\left(\mathrm{sO}_{2}\right)$, fractions of oxyhaemoglobin $\left(\mathrm{FO}_{2} \mathrm{Hb}\right)$, carboxyhaemoglobin (FCOHb), methaemoglobin (FMetHb), deoxyhaemoglobin $(\mathrm{FHHb})$, and foetal haemoglobin $(\mathrm{FHbF})$. The ABG analyser is used to monitor blood acid-base status $(\mathrm{pH})$, electrolytes (chloride, calcium, potassium, and sodium ions), and metabolites (blood glucose and lactate). Ventilation data are recorded on a breath-by-breath basis using inbuilt software of the Galileo ventilator. Readings of pulmonary static compliance are recorded from the ventilator at predetermined intervals.

In some animal models, electrical impedance tomography (EIT) is used to determine the spatial impedance distribution in a body cross-section by providing a dynamic, breath-to-breath measurement of both global and regional ventilation [107, 108]. EIT monitoring has the potential to become a noninvasive bedside tool for assessment of regional lung ventilation and lung recruitment in patients with acute respiratory failure [107-112].

3.1.6. Microcirculation and Tissue Monitoring. Concomitant monitoring of the macro- and the microcirculation using sidestream dark-field (SDF) imaging is often necessary in studies investigating shock and mechanisms of organ injury. For example, in the studies that examine the tissue effects of resuscitation with various fluids and blood products in ovine models of haemorrhage, trauma, and sepsis, real-time tissue oxygenation [113-116] is monitored by the insertion of oxygen probes (OxyFlow, Optronix, Oxford, UK) into the brain, heart, renal cortex, liver, and skeletal muscle. Tissue perfusion [113-116] is monitored by the insertion of Laser Doppler Flow probes (MNP100XP or MNP110XP, OxyFlow, Optronix, Oxford, UK) into the brain, heart, renal cortex, liver, and skeletal muscle. Tissue metabolism is monitored by the insertion of microdialysis [117-121] catheters into the anterior surface of the left ventricle, renal cortex, liver, skeletal muscle, and the femoral artery. These monitoring techniques are technically demanding; therefore, standardisation of anaesthesia, resuscitation and haemodynamic support practices, and strict implementation of study protocol are crucial to procuring quality data. Details of available techniques to monitor the microcirculation are beyond the scope of this paper and can be found elsewhere [113-116].

\subsubsection{Temperature, Fluid, Vasoactive Drugs, and Electrolyte} Management. Continuous temperature recording is important in order to detect hypo- or hyperthermia in a timely manner and institute corrective measures [122]. Animal patients lose body heat very rapidly when anaesthetised and precautions should be taken to avoid this [122, 123]. Temperature is managed using a circulating warm water mattress attached to either the warm water pump cooler or heater (Hemotherm, Cincinnati, OH, USA). Maintenance fluids (compound sodium lactate, Plasma-Lyte 148 Replacement, dextrose solutions, dextrose/saline solutions, or $0.9 \%$ sodium chloride solution) are delivered intravenously at $38-39^{\circ} \mathrm{C}$ and generally run throughout studies at a rate of $2 \mathrm{~mL} / \mathrm{kg} / \mathrm{hr}$ or at $10 \mathrm{~mL} / \mathrm{kg} / \mathrm{hr}$ during surgical interventions. Additional fluid boluses may be required to maintain blood pressure (BP) and $\mathrm{CO}$ as both $\mathrm{BP}$ and $\mathrm{CO}$ are clinically relevant to achieve mean arterial pressure (MAP) $>65 \mathrm{mmHg}$ and $\mathrm{CO}>3.0 \mathrm{~L} / \mathrm{min}$. Dopamine infusion ( $1 \mathrm{mg} / \mathrm{mL}$ preparation) titrated to effect is utilised as an inotrope if there is evidence of tissue hypoperfusion despite the fact that normal or elevated SVR occurs. Noradrenaline infusion $(60 \mu \mathrm{g} / \mathrm{mL})$ is commenced and titrated to effect if there is a decrease in $\mathrm{BP},+/-$ a decrease in CO, and a decrease in SVR. These haemodynamic parameters are a rough guide only and may vary between experiments depending on the research question for a given study. In our experience with vasoactive drugs in sheep, glyceryl trinitrate is associated with poor outcomes. Dobutamine causes profound tachycardia. Adrenaline is given in very minute doses if required. Hydralazine and sodium nitroprusside are great in decreasing afterload. Amiodarone when indicated in the management of dysrhythmias is given in minute doses by slow infusion as sheep are very prone to heart block. Maintenance fluids are changed to 5\% dextrose in normal saline if blood glucose drops below $2 \mathrm{mmol} / \mathrm{L}$. Potassium chloride solution infusion is given to achieve measured $\mathrm{K}^{+}$of $3-5 \mathrm{mmol} / \mathrm{L}$ at a titrated rate of $5-20 \mathrm{mmol} / \mathrm{hr}$ as needed. In case of persistent dysrhythmias, $20 \mathrm{mmol}$ of magnesium sulphate solution is given over $30 \mathrm{~min}$. Calcium chloride makes sheep extremely tachycardiac; therefore, we give calcium gluconate in $2.2 \mathrm{mmol}$ boluses to achieve a measured $\mathrm{Ca}^{2+}$ above $1 \mathrm{mmol} / \mathrm{L}$. Bicarbonate levels are corrected with sodium bicarbonate infusion if the animal is critically ill and acidotic depending on the bicarbonate deficiency.

3.1.8. Ovine Blood Collection, Storage, and Transfusion. Healthy adult sheep permit the collection of a unit of whole blood $(\sim 400 \mathrm{~mL})$ into standard human blood collection bags $[20,124]$. Blood is collected through a venous sheath in the EJV into Leukotrap WB blood bags (Pall Medical UK), incubated, leukofiltered, and manually separated into plasma and packed red blood cells (PRBCs) using a plasma extractor (Fenwal, Baxter, USA). The PRBCs are resuspended in salineadenine-glucose-mannitol (SAG-M) additive solution and stored at $2-6^{\circ} \mathrm{C}$, while plasma is frozen at $-20^{\circ} \mathrm{C}$ [124]. Human cross-matching protocols have been modified for sheep, and our observations have detected 18.2\% incompatibility between ovine PRBCs (ovPRBCs) and potential recipient sheep $[20,125]$. This highlights the importance of cross-matching especially in transfusion models [20, 124].

3.1.9. Sample Collection and Processing. An indwelling Foley urinary catheter is inserted urethrally in ewes and attached to a urine collection bag for measurement of urinary output and to facilitate urine sampling for urinalysis. Blood samples are taken via the facial arterial line or central venous line only 
and processed for submission to the laboratory or instantly for blood gas analysis. Bronchoalveolar lavage (BAL) and exhaled breath condensate samples are taken at time points determined by the individual studies.

3.1.10. Euthanasia Technique. At completion of experiments, animals are euthanized with intravenous administration of sodium pentobarbitone $325 \mathrm{mg} / \mathrm{mL}$ (Lethabarb, Virbac, Australia) at $0.5 \mathrm{~mL} / \mathrm{kg}$. Death of the animal is confirmed by the loss of cardiac electrical activity, blood pressure, cardiac output, and reflex activity.

3.1.11. Postmortem Handling and Disposal. A mid-ventral sternotomy or lateral thoracotomy (depending on the model) and coeliotomy are performed. The organs of interest are examined in situ before being harvested. Tissue samples for gene expression analysis are collected in RNAlater solution (Life Technologies, Thermo Fisher Scientific Inc.) or snap frozen in liquid nitrogen before being stored at $-80^{\circ} \mathrm{C}$. Histological samples are taken and fixed in formalin for later processing and staining. The rest of the animal remains are frozen and stored until being able to be disposed of via high temperature incineration.

\subsection{Animal ICU Equipment and Point-of-Care Technology.} All studies use the same standard setup for advanced haemodynamic monitoring, mechanical ventilation, and fluid therapy (Table 3 ). Individual studies may require additional sets of equipment and operating table preparation. Figure 2 depicts the theatre setup for ECMO studies.

An intensive care ventilator (Galileo, Hamilton Medical AG, Switzerland) is utilised for mechanical ventilation. This advanced microprocessor controlled intensive care ventilator offers a full spectrum of capabilities, including invasive, noninvasive, and advanced ventilation modes plus tube resistance compensation. It also allows inhalational delivery of drugs. The expiratory gas condensate samples are collected via an accessory attachment for a double surface condenser attached to a chiller (Digital Temperature Controller model 9102, PolyScience, IL, USA). Contemporary ventilators are versatile in that they have multiple modes of pressure or volume controlled cycles. Ventilator terminology, settings, patient setup, monitoring, and some of the common complications associated with mechanical ventilation are beyond the scope of this paper and readers are referred elsewhere [126]. In the era of lung-protective mechanical ventilation using limited tidal volumes, higher respiratory rates are applied to maintain adequate minute volume ventilation. Patient-ventilator dyssynchrony can be a problem during mechanical ventilation and can lead to patient discomfort and an increased work of breathing [126-132]. To minimise patient-ventilator dyssynchrony, the sheep are ventilated to achieve $\mathrm{ETCO}_{2}$ below $30 \mathrm{mmHg}$, which inhibits the spontaneous respiratory drive, therefore avoiding the use of neuromuscular blocking drugs. Proper interpretation of ventilator waveforms affords the critical care clinician a better understanding of the patient's respiratory function, response to therapy, and causes of patient-ventilator dyssynchrony [132]. The ventilator also acts as a ventilation meter, respiratory rate monitor, and apnoea alarm.

The ABL800 Flex (Radiometer, Copenhagen, Denmark) analyser is used for blood gas analysis. This analyser measures any combination of $\mathrm{pH}$, blood gas, electrolyte, oximetry, and metabolite parameters. It can measure up to 18 parameters on the same blood sample. The refrigerated Sigma $2-16 \mathrm{PK}$ (Sigma, Germany) centrifuge is used for spinning blood and BAL samples for submission to the laboratory. This centrifuge has the microhaematocrit spinning capabilities for point-of-care measurement and monitoring of packed cell volume $(\mathrm{PCV})$. A clinical veterinary refractometer is used for measuring and monitoring plasma protein and urine specific gravity. A bronchoscope (Olympus) is used for examining the trachea and bronchi and for bronchoalveolar lavage. A large animal laryngoscope is used to facilitate endotracheal intubation. We utilise the mobile C-arm X-ray generator with a flat detector (Veradius Neo, Royal Philips Electronics, The Netherlands) for radiography or fluoroscopy to verify placement and migration of invasive catheters and for experimental data collection as required.

Tissue chemistry analysis is accomplished with patientside microdialysis equipment which includes the microdialysis pumps CMA 107 and CMA/102 (CMA Microdialysis AB, Solna, Sweden) and the point-of-care microdialysis analyser (ISCUSflex, M Dialysis AB, Solna, Sweden). The ISCUSflex analyser takes measurements to monitor tissue chemistry from within microdialysis samples taken from virtually any tissue or organ in the body. Up to six different metabolites (glucose, lactate, pyruvate, glycerol, glutamate, and urea are assayed) provide unique opportunities for early detection of metabolic crisis and ischemia and for guiding therapeutic interventions. Tissue oxygenation and blood flow monitors are used for continuous monitoring. These machines permit continuous and simultaneous measurement of tissue oxygenation, blood flow, and temperature from the same probe or tissue microregion.

In addition to the traditional measurement of activated clotting time (ACT) of whole blood at point-of-care with a cage-side blood clotting system (Hemochron, ITC, NJ, USA), there are two pieces of equipment for advanced coagulation studies. These include the rotating pin thromboelastometry (ROTEM, Tem International GmbH, Munich, Germany) and the multiple platelet function analyser (Multiplate, Verum Diagnostica GmbH, Munich, Germany). The ROTEM uses thromboelastometry to determine if haemorrhage is caused by surgical bleeding, platelet dysfunction, clotting factor insufficiency, fibrin insufficiency, or hyperfibrinolysis [133138]. The Multiplate uses impedance aggregometry to assess platelet function in whole blood [139-143].

3.3. Data Capture and Archiving. We have developed novel techniques for electronic data collection and extraction. Digital data are collected and saved in a computer hard drive from the Marquette monitor as 5-second snapshots of the current values of the variables, the ventilator as breath-by-breath, the ECMO pump at 5-second intervals, and haemodynamic data by the Vigilance II at 2-second intervals. 
TABLE 3: Categories of animal intensive care unit (ICU) theatre devices used in ovine models of critical care research at the Critical Care Research Group (CCRG) Laboratory.

\begin{tabular}{|c|c|c|}
\hline Continuous monitors & Life support & Point-of-care technology \\
\hline Global & (i) Fluid pumps & (i) Blood gas analysis \\
\hline $\begin{array}{l}\text { (i) Cardiovascular (ECG, ABP, HR, CVP, CCO, and } \\
\mathrm{SvO}_{2} \text { ) }\end{array}$ & (ii) Mechanical ventilators & (ii) Centrifuges \\
\hline $\begin{array}{l}\text { (ii) Respiratory oxygenation }\left(\mathrm{SPO}_{2}\right) \text {, ventilation } \\
\left(\mathrm{ETCO}_{2} \text { and EIT }\right)\end{array}$ & (iii) Patient warming sources & (iii) Refractometer \\
\hline (iii) Core body temperature & (iv) Oxygen delivery & (iv) Microdialysate analysers \\
\hline (iv) Neurological monitoring (cEEG) & (v) Suction apparatus & (v) Multiplatelet function \\
\hline Regional & (vi) ECMO & (vi) Rotational thromboelastometry \\
\hline (i) Tissue oximetry & (vii) RRT & (vii) Fluoroscopy \\
\hline (ii) Tissue perfusion & (viii) HFOV & $\begin{array}{l}\text { (viii) Surface and intracardiac echocardiography } \\
\text { (USCOM and iCATHe) }\end{array}$ \\
\hline \multirow[t]{3}{*}{ (iii) Tissue metabolism } & (ix) VADs & (ix) Renal Doppler \\
\hline & (x) TAH (BiVACOR) & \\
\hline & (xi) Inhaled NO therapy & \\
\hline
\end{tabular}

ECG: electrocardiograph; ABP: arterial blood pressure; HR: heart rate; CVP: continuous venous pressure; $\mathrm{CCO}$ : continuous cardiac output; $\mathrm{SvO}_{2}$ : mixed venous oxygen saturation; $\mathrm{ETCO}_{2}$ : end tidal carbon dioxide partial pressure; EIT: electrical impedance tomography; cEEG: continuous electroencephalogram; ECMO: extracorporeal membrane oxygenation; RRT: renal replacement therapy; HFOV: high frequency oscillatory ventilation; NO: nitric oxide; USCOM: ultrasonic cardiac output monitor; iCATHe: intracatheter echocardiography; VADs: ventricular assist devices; TAH: total artificial heart.

Analogue signals, if available, are routed into custom written software and recorded at an appropriate frequency, often $200 \mathrm{~Hz}$ or $1 \mathrm{kHz}$. During data collection, if the original signals are not optimum, for instance, a poor ECG, a damped ABP, or the oximeter probe is not attached, then the extracted data will reflect this as either missing data or incorrect data. Human error may also play a role especially due to fatigue or unfamiliarity with patient monitors. The data acquisition programme may crash and may not restart soon enough for continuity of the data.

Data are extracted in text form from the files quasiautomatically using an assortment of purpose written programmes and macros into proprietary computer spread sheets. Each study is in a directory based on the date and time. Automated extraction, albeit practical, can lead to some glitches; for instance, if a variable is missing or inaccurate at an exact point, it will be extracted as it is. Data once captured is prospectively analysed to ensure integrity and quality.

\subsection{Synopses of Validated Ovine Models and Related Studies}

3.4.1. ECMO Studies. The sheep ECMO model is a multifaceted study that was designed to investigate alterations in inflammation and coagulation, drug pharmacokinetics, ECMO induced organ injury, novel echocardiography techniques, and oxidative stress levels during venovenous (VV) ECMO [2, 13-15]. The study also seeks to understand the pathophysiology of ECMO and to determine if the transfusion of aged compared to fresh ovine packed red blood cells (PRBCs) acts to compound ECMO inflammation leading to tissue injury. VV-ECMO is a form of extracorporeal respiratory support, where venous blood is drained from the patient to a gas exchange device (oxygenator) via cannulae placed in a large central vein. Blood then becomes enriched

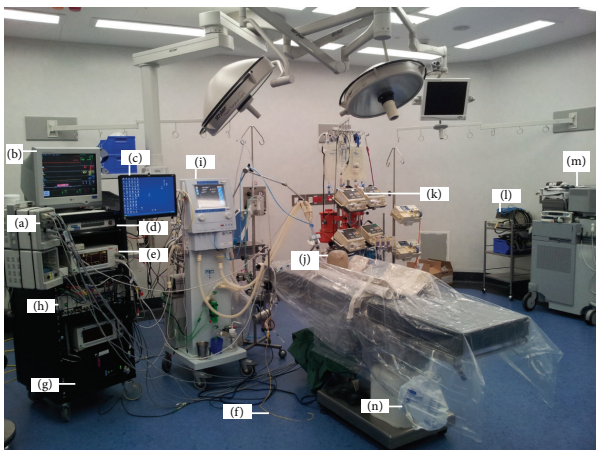

FIgURE 2: Standard animal intensive care unit (ICU) theatre of the Critical Care Research Group (CCRG). For continuous haemodynamic monitoring, the Marquette Solar 8000 Patient ICU CCU Monitoring System (GE Healthcare, Waukesha, WI, USA) consisting of modules (a), displays ( $b$ and $c$ ), and processor unit (d) together with Vigilance II monitor (e) coupled with Swan-Ganz CCOmbo pulmonary artery catheter (f) (Edwards Lifesciences, Irvine, CA, USA) are used. Other accessories include the hard $\operatorname{disc}(\mathrm{g})$ for data storage and an analogue to digital data converter (h). Recruitment of the intensive care ventilator Galileo (Hamilton Medical AG, Switzerland) (i) is performed with the aid of an Ohmeda breathing bag (j) before every experiment. Fluids and medications are delivered from the intravenous fluid workstation (k). Some experiments require the use of an electrosurgical unit (l) and echocardiography (m). All animals have bladder catheters and urine is collected in a sterile bag $(n)$.

with oxygen, has carbon dioxide removed, and is returned to the right atrium. VV-ECMO is a viable option in critically ill patients with potentially reversible respiratory failure who fail conventional treatment. Ongoing refinements in ECMO technology and clinical delivery may further improve patient 


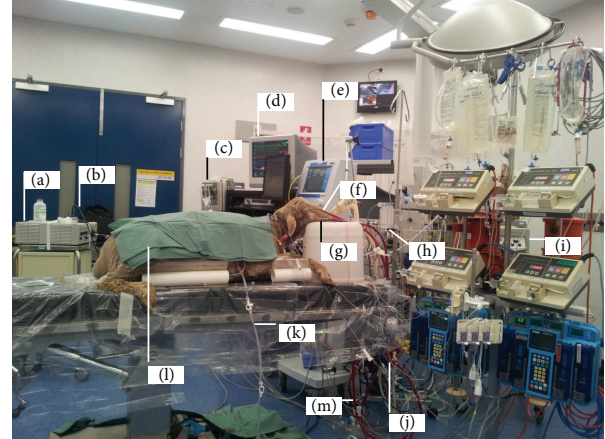

FIGURE 3: Sheep on venovenous extracorporeal membrane oxygenation (VV-ECMO). Equipment includes the Stryker light source (a) attached to an Olympus bronchoscope (b) for bronchoscopy and bronchoalveolar lavage. The Marquette Solar 8000 Patient ICU CCU Monitoring System (GE Healthcare, Waukesha, WI, USA) (c) and monitor (d). The Galileo ICU ventilator (e). ECMO return (f) and access cannulae (b), respectively. The pump assembly consisting of the non-CE marked air-oxygen mixture $\left(\mathrm{FiO}_{2}\right)$ (Sechrist, Anaheim, CA, USA) (h). CE marked ECMO 550 BioConsole Bio-Medicus (Medtronic Bio-Medicus Inc., Eden Prairie, MN, USA) (i). CE marked artificial lung (Quadrox PLS) oxygenator (j). Chest drain (K). Sheep (l). Permanent Life Support (PLS) ECMO circuit (MAQUET Cardiopulmonary AG, USA) (m). The Rotaflow Centrifugal Pump and surface coated circuitry, the console pump speed controller (Medtronic) with external drive head, and the heating source are not visible.

outcomes. A typical ECMO animal setup is illustrated in Figure 3.

3.4.2. TRALI Studies. TRALI is considered the most frequent cause of transfusion-related morbidity and mortality; however, the mechanism by which it develops remains to be fully elucidated $[76,125]$. Crucial to this is the development of clinically relevant animal models. Thus, our group developed the first large animal model of TRALI, using sheep. In this model, sheep were anaesthetised and instrumented and then infused with Escherichia coli lipopolysaccharide (LPS) to simulate bacterial infection, which is one of the risk factors for the development of TRALI. Sheep were then given a $10 \%$ transfusion with aliquots of pooled supernatant prepared from date-of-expiry human blood products (either day 5 platelet units or day 42 PRBC units) to provoke the development of TRALI. Control sheep received saline as a control first insult and pooled supernatants from equivalent fresh (day 1) human blood products as a control second insult. In this model, as in clinical cases, TRALI was defined by the development of hypoxaemia $\left(\mathrm{PaO}_{2} / \mathrm{FiO}_{2}<300\right.$ on $\mathrm{ABG}$ analysis) and pulmonary oedema (diagnosed by blinded histological assessment of postmortem lung sections), and $80 \%$ of LPS-treated sheep that were transfused with the dateof-expiry supernatant developed TRALI. This indicated the importance of both recipient and blood product factors in TRALI, providing further evidence of a two-event model of TRALI pathogenesis. While the incidence of TRALI was identical between these two groups, the physiological changes associated with TRALI induced by PRBC supernatant appeared to be more severe than those induced by the platelet supernatant, with higher PAP and CVP and lower CO. Further studies using the ovine TRALI model are planned to investigate the role that prestorage leucodepletion of blood products may have upon the development of TRALI as well as whether specific protein or lipid factors that form part of the storage lesion of blood products may individually, or in combination, induce TRALI.

3.4.3. Proteogenomic Studies to Understand Selective Susceptibility to Endotoxin. During later TRALI experiments, Chemonges and colleagues [144] observed that "some sheep were more susceptible to the effects of LPS than others from the same mob. As a result, the more susceptible sheep required considerably less LPS to prime their immune system. It is not known why this observation occurred, despite the sheep being the same breed, with similar characteristics. This striking observation of differential susceptibility to LPS has prompted new studies that are seeking to explain the variation" by way of proteogenomic characterisation of circulating acute phase markers and their bioassay development in sheep. This seed study is designed to characterise the selective resistance to the effects of endotoxin; to understand the role of genetic traits, molecular mechanisms, and products associated with the selective susceptibility to endotoxin during priming of the immune system; and to develop comprehensive acute phase protein and circulating microRNA profiles in sheep exposed to endotoxin [144].

3.4.4. CRASH-Sepsis and CRASH-Haemorrhage Studies. These studies are investigating the effects of trauma, haemorrhage, and infection on various tissue beds. In addition, the effects of resuscitation with various intravenous fluids and fresh and stored blood are also being investigated [20]. These models will provide ideal platforms for investigating the interactions between macroand microcirculation and the effects of various resuscitation targets and techniques on tissue homeostasis. These studies utilise holistic tissue monitoring that includes tissue chemistry analysis, tissue oxygenation, and perfusion measurement using techniques described in earlier sections.

3.4.5. Studies on Acute Smoke Inhalation Lung Injury. Pulmonary injury from acute smoke inhalation is a major cause of morbidity and mortality in burns patients [144]. The validated S-ALI model [25] has been very useful in investigating many areas of lung injury and acute respiratory distress syndrome (ARDS) and in understanding the basis of management of lung injury [145]. This model has been used successfully in many experiments such as ovine ECMO and investigations into the management of inhalational lung injury (Figure 4). One of such studies aimed to analyse the effects of nebulising an amphoteric, hypertonic chelating agent for pulmonary decontamination immediately following a standard smoke inhalation injury. It showed a promising treatment strategy for victims of smoke inhalation using an inhalation injury model [25]. 


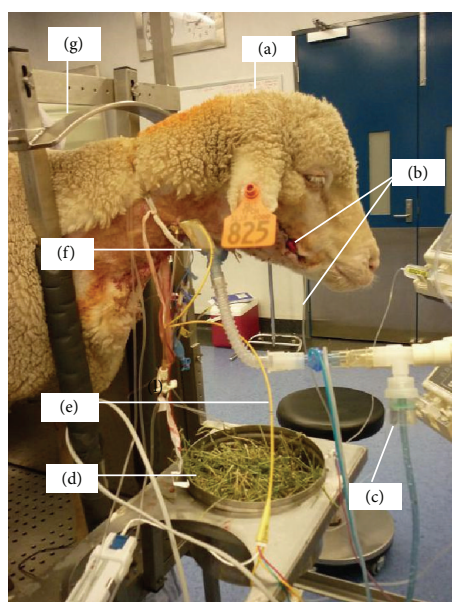

FIGURE 4: Ovine model of smoke inhalation injury. Nebulisation in a conscious sheep (a) in standing position following smoke inhalation via tracheostomy. Anaesthesia was induced using propofol $4 \mathrm{mg} / \mathrm{kg}$ IV and maintained with continuous infusion of midazolam $0.7 \mathrm{mg} / \mathrm{kg} / \mathrm{hr}$ IV and ketamine $8 \mathrm{mg} / \mathrm{kg} / \mathrm{hr}$ IV to facilitate instrumentation before allowing the sheep to recover. The right facial artery was cannulated to facilitate continuous arterial blood pressure monitoring and serial arterial blood gas analysis (b). Diphoterine or saline was placed in the nebuliser (c) and the sheep had free access to food (d). A Swan-Ganz pulmonary artery catheter (e) was inserted for continuous monitoring of pulmonary artery pressure, central venous pressure, and continuous cardiac output using thermodilution technique. The animal was ventilated through an open surgical tracheostomy (f). The crush (g) prevented the sheep from making large movements that could dislodge the attached instruments. Animals were monitored for up to 21 hours following instrumentation before being sacrificed.

3.4.6. The Ovine Brain Stem Death (BSD). The sheep BSD model provides a tool for the investigation of a wide array of mediators and also the effect of brain stem death on many organs $[26,27]$. Brain death causes significant physiologic stress that injures transplantable organs. This reduces the number of transplantable organs, increases posttransplant dysfunction, and contributes to rejection. Large animal models are required to further study pathologic mechanisms contributing to the insult seen in these organs as other current models are of short duration and do not reflect clinical reality. Studies that developed a clinically relevant large animal model of brain death using sheep and investigated the physiological responses that occur over 24 hours have been completed (unpublished data). After initial cannulation and anaesthesia using the techniques described above, an intracranial burr hole was established for insertion of an intracranial pressure monitoring device. For animals randomised to brain death, another cranial burr hole was made and an extradural foley catheter was inserted. This was inflated with $20-30 \mathrm{~mL}$ saline to reproduce a rapidly expanding intracranial lesion leading to brain hypoperfusion and brain death. Appropriateness of volume was additionally assessed by further inflation of small aliquots $(1 \mathrm{~mL})$ saline into the catheter until the point that no further sympathetic response was obtained. Intracranial pressure was maintained above the mean arterial pressure for $30 \mathrm{~min}$. The criteria used for ascertaining the establishment of BSD were negative cerebral perfusion pressure for $30 \mathrm{~min}$, loss of corneal and papillary reflexes, and no cough on bronchoscopy. Ketamine and alfaxalone were reduced to $2 \mathrm{mg} / \mathrm{hr}$ and $1 \mathrm{mg} / \mathrm{hr}$ after the diagnosis of brain death. Midazolam was ceased if it had been used. The animals were then maintained for 24 hours at which point they were sacrificed. The sheep received care similar to a human donor, including vasopressors, inotropes, and hormonal therapy $[26,27]$. The brain dead animals displayed significant elevations in heart rate, mean arterial pressure, and cardiac index on induction of brain death. Physiologic data has demonstrated that pulmonary pressure significantly increased after brain death and remained elevated for 24 hours. This may contribute to cardiac injury and the right ventricular dysfunction seen after transplantation. This model has been used to investigate the effect of an endothelin antagonist drug on preservation of the cardiopulmonary function following brain death [27]. Studies such as this have the potential to develop techniques to improve the availability and quality of donor organs for transplantation [27].

\subsubsection{BiVACOR and BiVAD Artificial Heart and the Ovine} Left Ventricular Assist Device (LVAD). BiVACOR is a novel rotary total artificial heart which is being developed in part by our group to treat global end-stage heart failure [21-23]. Studies are ongoing and preclinical prototypes have been tested by our group on an ovine model for the artificial heart. Our studies have assessed the haemodynamic performance of the dual pumping device during biventricular assistance (BiVAD) and total artificial heart (TAH) support, whilst assessing the ability to simultaneously alter the left/right heart chamber outflows successfully. We have also assessed the use of dual rotary LVAD systems to provide biventricular support. In these studies, haemodynamic and pump parameters were captured at $100 \mathrm{~Hz}$ using a dSPACE acquisition system (DS1103, dSPACE, MI, USA). Systemic and pulmonary flow rates were measured using clamp on perivascular flow sensors (MC20PAU, Transonic Systems, NY, USA) connected to a perivascular flow meter (T402-PP, Transonic Systems, NY, USA). Circulatory and pump pressures were recorded using silicon-based transducers (PX181B-015C5V, Omega Engineering, CT, USA). Figure 5 shows an anaesthetised sheep with a median sternotomy being prepared for artificial heart implant studies.

3.4.8. Studies to Assess Cerebral Microcirculation. The aim of this model is to describe a novel transseptal catheterisation technique for the injection of colour-coded microspheres for the assessment of cerebral microcirculation [28]. Transseptal catheterization refers to the intracardiac puncture of the interatrial septum with the intention of accessing the left atrium from the right atrium, by a technique originally developed by Ross [146]. The targeted area in a transseptal catheterization is the fossa ovalis (FO), as it is the thinnest region within the septum. Guidance of the procedure as well as identification of the FO is facilitated by fluoroscopy [147] and ultrasonography [148]. After insertion of the transseptal 


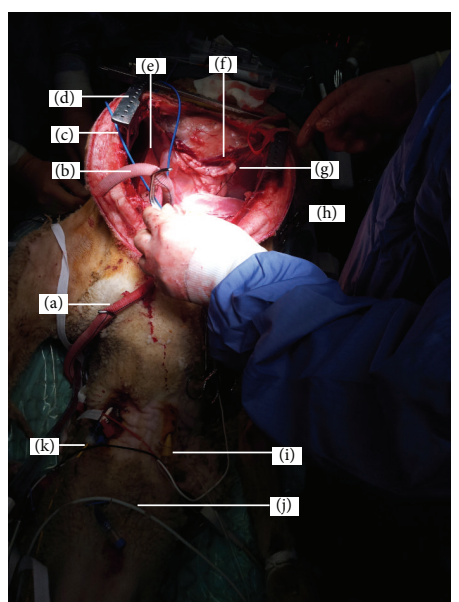

FIGURE 5: Implanting an artificial heart in an ovine model. This study evaluated a biventricular mechanical device called BiVACOR that is being developed for patients with end stage heart failure. Sheep are anaesthetised and maintained as in humans undergoing cardiac transplantation. In this sheep model, anaesthesia is maintained by constant infusion of propofol and fentanyl. The approach to the heart is via a median sternotomy. Anastomoses to prosthetic blood vessels are created on the pulmonary vein (a) and artery (b) and dorsal aorta and clamped for subsequent attachment to the BiVACOR system (not pictured). In our completed trials, we attached grafts via an end-to-end anastomosis to the ascending aorta ( $16-18 \mathrm{~mm}$ ) and pulmonary artery $(20 \mathrm{~mm})$ for left and right pump outflows, respectively. Inflow connections were achieved by removing the ventricles just below the atrioventricular groove (leaving about $1 \mathrm{~cm}$ of ventricular tissue) and suturing $38 \mathrm{~mm}$ grafts (end-to-end) to the ventricular tissue. All grafts were then attached to the pump. Blood flow after the prosthetic heart implant can be monitored by flow meters via probes (c). The surgical exposure of the chest cavity is maintained by a retractor (d) to visualise all organs. The right lung (e), diaphragm, and heart (h) are visible. A stay suture (g) facilitates the suspension of major blood vessels during dissection. Intravenous access for fluid administration was facilitated via a large bore catheter (i). Note the white colour of propofol $(j)$ being used to maintain anaesthesia. During dissection and prior to the removal of the ventricles, continuous haemodynamic monitoring is achieved via the Swan-Ganz pulmonary artery catheter $(\mathrm{k})$.

catheter and confirmation of its correct positioning, 4 million colour-coded spheres of 15-micron diameter each are injected hourly (E-Z TRAC; Interactive Medical Technology, Los Angeles, CA) as previously described [149]. Randomly assigned colours are attributed to each injection time in order to minimise selection biases, as previously described [65, 150]. The distribution of the microspheres in brain tissue can then be determined by cytometry in specific laboratories. The novelty of this technique is that cerebral blood flow changes can be assessed over time, as each different colour assigned to a specific time point will be differentiated during count.

\section{Discussion}

This paper is probably the first to document the varied anaesthetic and data collection techniques, monitoring devices, and point-of-care instruments utilised in ovine biomedical research. The disparity in techniques is probably due to study specific requirements, familiarity of use, and availability of equipment in specific research settings. Also, in some reports, little information is published about the monitoring and the fate of the animal model, which leaves information gaps, therefore limiting the understanding of the reproducibility or translatability of those studies. The latter prompted us to present the practices used by our research group, describing animal ICU monitoring practices as a model for ovine biomedical studies. Meticulous monitoring of anaesthetised animals is essential as failure to detect warning signs of impending disaster results in a dead or impaired animal $[151,152]$.

Our studies are important in that complex and validated ovine models may, to some extent, be comparable to other animal models such as swine that can generate robust mechanistic data that lend themselves to translational research. While each animal model has significant benefits in medical research, none is without weaknesses [153]. There is a dissenting debate that animal-based research is unable to predict human response because animals and humans have different evolutionary trajectories [58]. The alternative view is that animal models should be genetically closer to those of humans to be relevant [59]. Another potential obstacle in the use of sheep in whole animal experiments is that studies that enrol large animals can provoke intense scrutiny from regulatory oversight groups and journal editors, if not meticulously designed to address animal welfare concerns. Current animal ethics requirements emphasise the principle of replacement, refinement, and reduction (3Rs) in research using animals based on established guidelines [154]. Our studies showcase the 3 Rs by utilising rational study design that maximises the research opportunities in a given animal without compromising quality, using advances in technology and highly skilled personnel to minimise experimental attrition due to the unexpected loss of experimental animals.

Monitoring devices come in different varieties and can provide misleading information if they do not function correctly or are not properly configured. Artefacts do occur, thus underscoring the necessity for a clinician to physically check the animal first before assuming the instrument is faulty [7]. There is no device that replaces a trained person in monitoring an anaesthetised or even a conscious experimental animal. The studies whose monitoring methods are described here are multifaceted, expensive, and highly refined. They require meticulous planning, animal preparation, anaesthesia induction and maintenance, advanced physiologic monitoring, state-of-the-art data capture, pointof-care technology, and animal aftercare. This level of monitoring has worked successfully at the CCRG Laboratory; however, it may not always be possible to be used elsewhere. Different research establishments have different logistical constraints and perhaps have different goals with their experiments. It comes at a significant cost and is usually only possible in large establishments with appropriate research support and trained personnel. Electronic patient monitors require regular calibration, require software and hardware updating, can rapidly become obsolete, and can represent a 
significant financial investment. Also, the majority of devices available for monitoring animals were manufactured for use in humans, which may not necessarily be suitable for use in animals. Information on the description of the strengths, weaknesses, and rationale of each monitoring device relating to their use in sheep is still lacking. Moreover, there is no formal standard to act as a benchmark that evaluates the diverse equipment available for use in large animal ICUs. This in turn may influence investigators to only use or recommend the type of equipment available in their particular institution without consideration of the many other options available in the market.

The full use of the available patient monitoring technology together with the extraction and archiving of considerable amounts of physiological data from every experimental animal has positive animal ethics implications. This ultimately minimises the need for repeat experiments by reducing animal numbers used for experiments and archived and reproducible information allows for a more effective transfer of knowledge to others involved in this area of research.

\section{Conclusions}

There are significant alternative approaches to anaesthesia and monitoring of ovine models, probably due to varied experimental goals. Considerable resource investment in technology is necessary to satisfy the needs of monitoring anaesthetised large animals to facilitate the gathering of robust and translatable research data. The experience of the professional and technical personnel equates to the equipment being utilised to their maximum capabilities for cutting edge animal research. Negligible deleterious outcomes when using ovine models are a result of familiarity and using a standardised approach to all aspects of animal care. This level of standard enables the understanding of emerging research tools such as proteogenomics and other new biomedical technologies in a laboratory setting, which highlights the importance of the utilisation of sheep in researching human disease. We have described a critical care setup with multiple ovine models enabling the study of very important aspects for the whole body animal experiments that could provide an alternative to other large animal models such as pigs.

\section{Conflict of Interests}

John F. Fraser and Daniel Timms have directorship interests in the firm developing the total artificial heart, BiVACOR. All the other authors declare that there is no conflict of interests regarding the publication of this paper.

\section{Acknowledgments}

Saul Chemonges is an Australian Postgraduate Award (APA) Scholar at The University of Queensland (UQ) and a Staff Member at Queensland University of Technology Medical Engineering and Research Facility (QUT-MERF). The animal studies described here were conducted at QUT-MERF and partly funded by The Australian Government National Health and Medical Research Council (NHMRC), The Prince Charles Hospital (TPCH) Foundation, The Critical Care Research Group (CCRG), The Royal Brisbane Women's Hospital (RBWH) Foundation, Queensland Emergency Medicine Research Foundation (QEMRF), GlaxoSmithKline Australia, Australian Red Cross Blood Service (the Blood Service), and Australian Government that fully funds the Blood Service for the provision of blood products for TRALI experiments and Queensland Health. Gratitude is extended to Andrew Gibbon, Mark Bishop, Dr. Roland Steck, Claudia Bartlett, Dr. Siamak Saifzadeh, Megan Wheeler, Leanne Conway, Dr. Katrina Whitting, and Anton Sanker for their help in the care of the animals and hospitality. The authors thank Margaret Passmore of UQ for the scientific contribution at the CCRG Laboratory and the CCRG administrative team specifically Lyn Munck, Andrea Floriani, and Laney Lawrence for their assistance in various capacities.

\section{References}

[1] D. L. Traber, M. O. Maybauer, D. M. Maybauer, M. Westphal, and L. D. Traber, "Inhalational and acute lung injury," Shock, vol. 24, supplement 1, pp. 82-87, 2005.

[2] K. Shekar, Y. L. Fung, S. Diab et al., "Development of simulated and ovine models of extracorporeal life support to improve understanding of circuit-host interactions," Critical Care and Resuscitation, vol. 14, no. 2, pp. 105-111, 2012.

[3] W. R. Hein and P. J. Griebel, "A road less travelled: large animal models in immunological research," Nature Reviews Immunology, vol. 3, no. 1, pp. 79-84, 2003.

[4] E. M. Walters, Y. Agca, V. Ganjam, and T. Evans, "Animal models got you puzzled?: think pig," Annals of the New York Academy of Sciences, vol. 1245, no. 1, pp. 63-64, 2011.

[5] T. Nunoya, K. Shibuya, T. Saitoh et al., "Use of miniature pig for biomedical research, with reference to toxicologic studies," Journal of Toxicologic Pathology, vol. 20, no. 3, pp. 125-132, 2007.

[6] P. Vodicka, J. K. Smetana Jr., B. Dvoránková et al., "The miniature pig as an animal model in biomedical research," Annals of the New York Academy of Sciences, vol. 1049, no. 1, pp. 161-171, 2005.

[7] S. C. Haskins, "Monitoring the anesthetized patient," Veterinary Clinics of North America-Small Animal Practice, vol. 22, no. 2, pp. 425-431, 1992.

[8] S. C. Haskins, "General guidelines for judging anesthetic depth," Veterinary Clinics of North America-Small Animal Practice, vol. 22, no. 2, pp. 432-434, 1992.

[9] T. Farry, "Monitoring the critical patient," in VeterInary Technician's Manual for Small Animal Emergency and Critical Care, C. L. Norkus, Ed., pp. 63-81, John Wiley \& Sons, 2012.

[10] J. C. Thurmon, W. J. Tranquilli, and G. J. Benson, Lumb and Jones' Veterinary Anesthesia and Analgesia, Williams \& Wilkins, 1996.

[11] L. W. Hall and K. W. Clarke, Veterinary Anaesthesia, Bailliere Tindall, 1991.

[12] A. C. V. Anon, "Anesthesiology guidelines developed," Journal of the American Veterinary Medical Association, vol. 206, pp. 936937, 1995.

[13] C. I. McDonald, Y. L. Fung, and J. F. Fraser, "Antioxidant trace element reduction in an in vitro cardiopulmonary bypass circuit," ASAIO Journal, vol. 58, no. 3, pp. 217-222, 2012. 
[14] K. Shekar, J. A. Roberts, S. Welch et al., "ASAP ECMO: antibiotic, sedative and analgesic pharmacokinetics during extracorporeal membrane oxygenation: a multi-centre study to optimise drug therapy during ECMO," BMC Anesthesiology, vol. 12, article 29, 2012.

[15] K. Shekar, J. A. Roberts, S. Ghassabian et al., "Altered antibiotic pharmacokinetics during extracorporeal membrane oxygenation: cause for concern?" The Journal of Antimicrobial Chemotherapy, vol. 68, no. 3, pp. 726-727, 2013.

[16] D. G. Platts, A. Hilton, S. Diab et al., "A novel echocardiographic imaging technique, intracatheter echocardiography, to guide veno-venous extracorporeal membrane oxygenation cannulae placement in a validated ovine model," Intensive Care Medicine Experimental, vol. 2, article 2, 2014.

[17] J. P. Tung, Y. L. Fung, M. Nataatmadja et al., "A novel in vivo ovine model of transfusion-related acute lung injury (TRALI)," Vox Sanguinis, vol. 100, no. 2, pp. 219-230, 2011.

[18] J.-P. Tung, J. F. Fraser, M. Nataatmadja et al., "Age of blood and recipient factors determine the severity of transfusion-related acute lung injury (TRALI)," Critical Care, vol. 16, no. 1, article R19, 2012.

[19] J.-P. Tung, J. F. Fraser, P. Wood, and Y. L. Fung, "Respiratory burst function of ovine neutrophils," BMC Immunology, vol. 10, article 25, 2009.

[20] Y. L. Fung, J. P. Tung, S. R. Foley et al., "Stored blood transfusion induces transient pulmonary arterial hypertension without impairing coagulation in an ovine model of nontraumatic haemorrhage," Vox Sanguinis, vol. 105, no. 2, pp. 150-158, 2013.

[21] B. Thomson, J. F. Fraser, D. Timms, J. Dunning, and K. Dunster, "Initial acute in vivo animal experience with the BiVACOR rotary bi-ventricular assist device," Heart, Lung and Circulation, vol. 18, no. 1, p. 84, 2009.

[22] D. Timms, E. Gude, N. Gaddum et al., "Assessment of right pump outflow banding and speed changes on pulmonary hemodynamics during biventricular support with two rotary left ventricular assist devices," Artificial Organs, vol. 35, no. 8, pp. 807-813, 2011.

[23] D. Timms, J. Fraser, M. Hayne, J. Dunning, K. McNeil, and M. Pearcy, "The BiVACOR rotary biventricular assist device: concept and in vitro investigation," Artificial Organs, vol. 32, no. 10, pp. 816-819, 2008.

[24] N. R. Gaddum, D. L. Timms, M. Stevens, D. Mason, N. Lovell, and J. F. Fraser, "Comparison of preload-sensitive pressure and flow controller strategies for a dual device biventricular support system," Artificial Organs, vol. 36, no. 3, pp. 256-265, 2012.

[25] T. Riedel, J. F. Fraser, K. Dunster, J. Fitzgibbon, and A. Schibler, "Effect of smoke inhalation on viscoelastic properties and ventilation distribution in sheep," Journal of Applied Physiology, vol. 101, no. 3, pp. 763-770, 2006.

[26] J. F. Fraser, M. Nataatmadja, M. Passmore, A. Corley, J. Dunning, and F. Kermeen, "Brain stem death induced pulmonary hypertension-more pronounced and prolonged than left ventricular changes in an ovine model," Heart, Lung and Circulation, vol. 18, no. 1, p. 74, 2009.

[27] R. P. Watts, O. Thom, and J. F. Fraser, "Inflammatory signalling associated with brain dead organ donation: from brain injury to brain stem death and posttransplant ischaemia reperfusion injury," Journal of Transplantation, vol. 2013, Article ID 521369, 19 pages, 2013.

[28] J. Bellapart, K. R. Dunster, S. Diab et al., "Intracardiac echocardiography guided transeptal catheter injection of microspheres for assessment of cerebral microcirculation in experimental models," Cardiology Research and Practice, vol. 2013, Article ID 595838, 8 pages, 2013.

[29] F. R. Murdoch, G. L. Maker, I. Nitsos, G. R. Polglase, and G. C. Musk, "Intraperitoneal medetomidine: a novel analgesic strategy for postoperative pain management in pregnant sheep," Laboratory Animals, vol. 47, no. 1, pp. 66-70, 2013.

[30] C. T. Quinn, A. L. Raisis, and G. C. Musk, "Evaluation of Masimo signal extraction technology pulse oximetry in anaesthetized pregnant sheep," Veterinary Anaesthesia and Analgesia, vol. 40, no. 2, pp. 149-156, 2013.

[31] V. P. Walsh, M. Gieseg, P. M. Singh, S. L. Mitchinson, and J. P. Chambers, "A comparison of two different ketamine and diazepam combinations with an alphaxalone and medetomidine combination for induction of anaesthesia in sheep," New Zealand Veterinary Journal, vol. 60, no. 2, pp. 136-141, 2012.

[32] S. Manodoro, M. Endo, P. Uvin et al., "Graft-related complications and biaxial tensiometry following experimental vaginal implantation of flat mesh of variable dimensions," BJOG, vol. 120, no. 2, pp. 244-250, 2013.

[33] A. Hamahata, P. Enkhbaatar, M. Lange et al., "Administration of a peroxynitrite decomposition catalyst into the bronchial artery attenuates pulmonary dysfunction after smoke inhalation and burn injury in sheep," Shock, vol. 38, no. 5, pp. 543-548, 2012.

[34] Y. Yamamoto, P. Enkhbaatar, H. Sakurai et al., "Development of a long-term ovine model of cutaneous burn and smoke inhalation injury and the effects of early excision and skin autografting," Burns, vol. 38, no. 6, pp. 908-916, 2012.

[35] M. O. Maybauer, D. M. Maybauer, J. F. Fraser et al., "Combined recombinant human activated protein $\mathrm{C}$ and ceftazidime prevent the onset of acute respiratory distress syndrome in severe sepsis," Shock, vol. 37, no. 2, pp. 170-176, 2012.

[36] J. Fenhammar, M. Rundgren, J. Forestier, S. Kalman, S. Eriksson, and R. Frithiof, "Toll-like receptor 4 inhibitor TAK-242 attenuates acute kidney injury in endotoxemic sheep," Anesthesiology, vol. 114, no. 5, pp. 1130-1137, 2011.

[37] M. Derwall, R. C. E. Francis, K. Kida et al., "Administration of hydrogen sulfide via extracorporeal membrane lung ventilation in sheep with partial cardiopulmonary bypass perfusion: a proof of concept study on metabolic and vasomotor effects," Critical Care, vol. 15, no. 1, article R51, 2011.

[38] P. Enkhbaatar, J. Wang, F. Saunders et al., "Mechanistic aspects of inducible nitric oxide synthase-induced lung injury in burn trauma," Burns, vol. 37, no. 4, pp. 638-645, 2011.

[39] N. Morita, P. Enkhbaatar, D. M. Maybauer et al., "Impact of bronchial circulation on bronchial exudates following combined burn and smoke inhalation injury in sheep," Burns, vol. 37, no. 3, pp. 465-473, 2011.

[40] M. Westphal, S. Rehberg, M. O. Maybauer et al., "Cardiopulmonary effects of low-dose arginine vasopressin in ovine acute lung injury," Critical Care Medicine, vol. 39, no. 2, pp. 357-363, 2011.

[41] D. M. Maybauer, M. O. Maybauer, C. Szabó et al., “The peroxynitrite catalyst WW-85 improves pulmonary function in ovine septic shock," Shock, vol. 35, no. 2, pp. 148-155, 2011.

[42] J. K. Cleal, M. Thomas, M. A. Hanson, S. Paterson-Brown, H. M. Gardiner, and L. R. Green, "Noninvasive fetal electrocardiography following intermittent umbilical cord occlusion in the preterm ovine fetus," BJOG, vol. 117, no. 4, pp. 438-444, 2010.

[43] A. Hamahata, P. Enkhbaatar, H. Sakurai, M. Nozaki, and D. L. Traber, "Sclerosis therapy of bronchial artery attenuates acute 
lung injury induced by burn and smoke inhalation injury in ovine model," Burns, vol. 36, no. 7, pp. 1042-1049, 2010.

[44] Y. Nakano, M. O. Maybauer, D. M. Maybauer, P. Enkhbaatar, and D. L. Traber, "A novel antibiotic based long-term model of ovine smoke inhalation injury and septic shock," Burns, vol. 36, no. 7, pp. 1050-1058, 2010.

[45] M. O. Maybauer, D. M. Maybauer, J. F. Fraser et al., "Recombinant human activated protein $\mathrm{C}$ attenuates cardiovascular and microcirculatory dysfunction in acute lung injury and septic shock," Critical Care, vol. 14, no. 6, article R217, 2010.

[46] T. Okutomi, R. A. Whittington, D. J. Stein, and H. O. Morishima, "Comparison of the effects of sevoflurane and isoflurane anesthesia on the maternal-fetal unit in sheep," Journal of Anesthesia, vol. 23, no. 3, pp. 392-398, 2009.

[47] J. F. Fraser, L. Cuttle, M. Kempf, G. E. Phillips, M. T. Hayes, and R. M. Kimble, "A randomised controlled trial of amniotic membrane in the treatment of a standardised burn injury in the merino lamb," Burns, vol. 35, no. 7, pp. 998-1003, 2009.

[48] A. Hamahata, P. Enkhbaatar, S. Hiroyuki, M. Nozaki, and D. L. Traber, "Effect of ablated bronchial blood flow on survival rate and pulmonary function after burn and smoke inhalation in sheep," Burns, vol. 35, no. 6, pp. 802-810, 2009.

[49] C. C. Jonkam, M. Lange, D. L. Traber et al., "Cardiovascular collapse and vascular permeability changes in an ovine model of methicillin-resistant staphylococcus aureus sepsis," Shock, vol. 32, no. 6, pp. 621-625, 2009.

[50] J. C. Mansel, D. J. Shaw, F. A. Strachan, A. Gray, and R. E. Clutton, "Comparison of peripheral and core temperatures in anaesthetized hypovolaemic sheep," Veterinary Anaesthesia and Analgesia, vol. 35, no. 1, pp. 45-51, 2008.

[51] N. Aksu, A. Seyahi, T. Aksu, Ç. Öztürk, S. Dervişoǧlu, and V. M. Murat Hiz, "Radiographic and pathological stages of the changes at the bone-cement interface: an in-vivo experimental study," Archives of Orthopaedic and Trauma Surgery, vol. 128, no. 10, pp. 1187-1191, 2008.

[52] S. E. Copeland, L. A. Ladd, X.-Q. Gu, and L. E. Mather, "The effects of general anesthesia on the central nervous and cardiovascular system toxicity of local anesthetics," Anesthesia and Analgesia, vol. 106, no. 5, pp. 1429-1439, 2008.

[53] M. Westphal, P. Enkhbaatar, F. C. Schmalstieg et al., "Neuronal nitric oxide synthase inhibition attenuates cardiopulmonary dysfunctions after combined burn and smoke inhalation injury in sheep," Critical Care Medicine, vol. 36, no. 4, pp. 1196-1204, 2008.

[54] D. M. Maybauer, M. O. Maybauer, C. Szabó et al., "Lungprotective effects of the metalloporphyrinic peroxynitrite decomposition catalyst WW-85 in interleukin-2 induced toxicity," Biochemical and Biophysical Research Communications, vol. 377, no. 3, pp. 786-791, 2008.

[55] L. J. Voss, G. Ludbrook, C. Grant, R. Upton, and J. W. Sleigh, "A comparison of pharmacokinetic/pharmacodynamic versus mass-balance measurement of brain concentrations of intravenous anesthetics in sheep," Anesthesia and Analgesia, vol. 104, no. 6, pp. 1440-1446, 2007.

[56] M. O. Maybauer, D. M. Maybauer, J. F. Fraser et al., "Ceftazidime improves hemodynamics and oxygenation in ovine smoke inhalation injury and septic shock," Intensive Care Medicine, vol. 33, no. 7, pp. 1219-1227, 2007.

[57] A. Quail, S. McIlveen, R. Bishop et al., "Autonomic control of bronchial blood flow and airway dimensions during strenuous exercise in sheep," Pulmonary Pharmacology and Therapeutics, vol. 20, no. 2, pp. 190-199, 2007.
[58] R. Bishop, D. McLeod, S. McIlveen et al., "Effects of graded exercise on bronchial blood flow and airway dimensions in sheep," Pulmonary Pharmacology and Therapeutics, vol. 20, no. 2, pp. 178-189, 2007.

[59] A. J. W. Fletcher, D. S. Gardner, C. M. B. Edwards, A. L. Fowden, and D. A. Giussani, "Development of the ovine fetal cardiovascular defense to hypoxemia towards full term," American Journal of Physiology-Heart and Circulatory Physiology, vol. 291, no. 6, pp. H3023-H3034, 2006.

[60] G. S. Hamilton, B. Edwards, P. Solin, and A. M. Walker, "A model of coronary artery endothelial dysfunction in the sleeping lamb," Sleep Medicine, vol. 7, no. 7, pp. 573-579, 2006.

[61] P. J. Peyton, Y. Venkatesan, S. G. Hood, P. Junor, and C. May, "Noninvasive, automated and continuous cardiac output monitoring by pulmonary capnodynamics: breath-by-breath comparison with ultrasonic flow probe," Anesthesiology, vol. 105, no. 1, pp. 72-80, 2006.

[62] S. L. Hoskins, G. I. Elgjo, J. Lu et al., "Closed-loop resuscitation of burn shock," Journal of Burn Care and Research, vol. 27, no. 3, pp. 377-385, 2006.

[63] V. P. Rao, T. Poutahidis, R. P. Marini, H. Holcombe, A. B. Rogers, and J. G. Fox, "Renal infarction and immune-mediated glomerulonephritis in sheep (Ovis aries) chronically implanted with indwelling catheters," Journal of the American Association for Laboratory Animal Science, vol. 45, no. 4, pp. 14-19, 2006.

[64] C. D. Myers, K. Mattix, R. G. Presson Jr. et al., “Twenty-four hour cardiopulmonary stability in a model of assisted newborn Fontan circulation," Annals of Thoracic Surgery, vol. 81, no. 1, pp. 264-271, 2006.

[65] D. M. Maybauer, M. O. Maybauer, L. D. Traber et al., "Effects of severe smoke inhalation injury and septic shock on global hemodynamics and microvascular blood flow in sheep," Shock, vol. 26, no. 5, pp. 489-495, 2006.

[66] M. O. Maybauer, D. M. Maybauer, J. F. Fraser et al., "Recombinant human activated protein $\mathrm{C}$ improves pulmonary function in ovine acute lung injury resulting from smoke inhalation and sepsis," Critical Care Medicine, vol. 34, no. 9, pp. 2432-2438, 2006.

[67] P. Enkhbaatar, K. Murakami, L. D. Traber et al., "The inhibition of inducible nitric oxide synthase in ovine sepsis model," Shock, vol. 25, no. 5, pp. 522-527, 2006.

[68] M. Westphal, R. A. Cox, L. D. Traber et al., "Combined burn and smoke inhalation injury impairs ovine hypoxic pulmonary vasoconstriction," Critical Care Medicine, vol. 34, no. 5, pp. 1428-1436, 2006.

[69] A. J. W. Fletcher, A. J. Forhead, A. L. Fowden, W. R. Ford, P. W. Nathanielsz, and D. A. Giussani, "Effects of gestational age and cortisol treatment on ovine fetal heart function in a novel biventricular Langendorff preparation," Journal of Physiology, vol. 562, no. 2, pp. 493-505, 2005.

[70] V. L. Webster, D. M. Cara, R. M. Walker, M. M. Ramsay, and A. R. Aitkenhead, "Description of a technique for anaesthetizing pregnant ewes for fetal surgery," Laboratory Animals, vol. 39, no. 1, pp. 94-99, 2005.

[71] J. G. Venegas, T. Schroeder, S. Harris, R. T. Winkler, and M. F. Vidal Melo, "The distribution of ventilation during bronchoconstriction is patchy and bimodal: A PET Imaging Study," Respiratory Physiology \& Neurobiology, vol. 148, no. 1-2, pp. 57-64, 2005.

[72] P. Enkhbaatar, Y. Kikuchi, L. D. Traber et al., "Effect of inhaled nitric oxide on pulmonary vascular hyperpermeability in sheep 
following smoke inhalation," Burns, vol. 31, no. 8, pp. 1013-1019, 2005.

[73] M. O. Maybauer, D. M. Maybauer, L. D. Traber et al., "Gentamicin improves hemodynamics in ovine septic shock after smoke inhalation injury," Shock, vol. 24, no. 3, pp. 226-231, 2005.

[74] M. O. Maybauer, Y. Kikuchi, M. Westphal et al., "Effects of manganese superoxide dismutase nebulization on pulmonary function in an ovine model of acute lung injury," Shock, vol. 23, no. 2, pp. 138-143, 2005.

[75] M. Westphal, S. Noshima, T. Isago et al., "Selective thromboxane A2 synthase inhibition by OKY-046 prevents cardiopulmonary dysfunction after ovine smoke inhalation injury," Anesthesiology, vol. 102, no. 5, pp. 954-961, 2005.

[76] J.-P. Tung, J. F. Fraser, M. Nataatmadja et al., "Age of blood and recipient factors determine the severity of transfusion-related acute lung injury (TRALI)," Critical Care, vol. 16, no. 1, article R19, 2012.

[77] National Health and Medical Research Council, Australian Code of Practice for the Care and Use of Animals For Scientific Purposes, NHMRC, Canberra, Australia, 2013.

[78] J. A. Dixon and F. G. Spinale, "Large animal models of heart failure; a critical link in the translation of basic science to clinical practice," Circulation: Heart Failure, vol. 2, no. 3, pp. 262-271, 2009.

[79] D. M. Maybauer, M. O. Maybauer, J. F. Fraser et al., "Ceftazidime reduces pulmonary hypertension in an ovine model of sepsis following smoke inhalation injury," Critical Care, vol. 9, supplement 1, P36 pages, 2005.

[80] W. Lu, W. K. Park, B. Uchida et al., "The ovine jugular vein as a model for interventional radiology procedures," Radiology and Oncology, vol. 42, no. 2, pp. 59-65, 2008.

[81] P. M. Taylor, "Effects of hypertonic saline infusion on the adrenocortical response to thiopental-halothane anesthesia in sheep after premedication with acepromazine," Veterinary Surgery, vol. 28, no. 1, pp. 77-82, 1999.

[82] P. M. Taylor, "Endocrine and metabolic responses in sheep during halothane and pentobarbitone anaesthesia with dobutamine infusion," Journal of Veterinary Pharmacology and Therapeutics, vol. 21, no. 1, pp. 62-68, 1998.

[83] P. M. Taylor, "Endocrine and metabolic effects of hypotension or halothane inhalation in sheep anaesthetized with pentobarbital," British Journal of Anaesthesia, vol. 80, no. 2, pp. 208-212, 1998.

[84] P. M. Taylor, "Anaesthesia in sheep and goats," In Practice, vol. 13, no. 1, pp. 31-36, 1991.

[85] B. O’Hagan, K. Pasloske, C. McKinnon, N. Perkins, and T. Whittem, "Clinical evaluation of alfaxalone as an anaesthetic induction agent in dogs less than 12 weeks of age," Australian Veterinary Journal, vol. 90, no. 9, pp. 346-350, 2012.

[86] S. Zaki, K. E. Ticehurst, and Y. Miyaki, "Clinical evaluation of Alfaxan-CD as an intravenous anaesthetic in young cats," Australian Veterinary Journal, vol. 87, no. 3, pp. 82-87, 2009.

[87] H. Keates and T. Whittem, "Effect of intravenous dose escalation with alfaxalone and propofol on occurrence of apnoea in the dog," Research in Veterinary Science, vol. 93, no. 2, pp. 904-906, 2012.

[88] A. Jackson, "In this issue-March 2009," Australian Veterinary Journal, vol. 87, no. 3, pp. 71-72, 2009.

[89] A. Andaluz, N. Felez-Ocaña, L. Santos, L. Fresno, and F. García, "The effects on cardio-respiratory and acid-base variables of the anaesthetic alfaxalone in a 2 -hydroxypropyl- $\beta$-cyclodextrin
(HPCD) formulation in sheep," Veterinary Journal, vol. 191, no. 3, pp. 389-392, 2012.

[90] R. G. Brower, M. A. Matthay, A. Morris, D. Schoenfeld, B. T. Thompson, and A. Wheeler, "Ventilation with lower tidal volumes as compared with traditional tidal volumes for acute lung injury and the acute respiratory distress syndrome," The New England Journal of Medicine, vol. 342, no. 18, pp. 1301-1308, 2000.

[91] C. L. Hough, R. H. Kallet, V. M. Ranieri, G. D. Rubenfeld, J. M. Luce, and L. D. Hudson, "Intrinsic positive end-expiratory pressure in Acute Respiratory Distress Syndrome (ARDS) network subjects," Critical Care Medicine, vol. 33, no. 3, pp. 527$532,2005$.

[92] J. H. Hanson and H. Flori, "Application of the acute respiratory distress syndrome network low-tidal volume strategy to pediatric acute lung injury," Respiratory Care Clinics of North America, vol. 12, no. 3, pp. 349-357, 2006.

[93] S. B. R. Kästner, S. Ohlerth, A. Pospischil, J. Boller, and M. K. Huhtinen, "Dexmedetomidine-induced pulmonary alterations in sheep," Research in Veterinary Science, vol. 83, no. 2, pp. 217226, 2007.

[94] G. Plicchi, E. Marcelli, M. Parlapiano, and T. Bombardini, "PEA I and PEA II based implantable haemodynamic monitor: pre clinical studies in sheep," Europace, vol. 4, no. 1, pp. 49-54, 2002.

[95] S. Garrigue, P. Bordachar, S. Reuter et al., "Comparison of permanent left ventricular and biventricular pacing in patients with heart failure and chronic atrial fibrillation: prospective haemodynamic study," Heart, vol. 87, no. 6, pp. 529-534, 2002.

[96] K. A. Otto and T. Gerich, "Comparison of simultaneous changes in electroencephalographic and haemodynamic variables in sheep anaesthetised with halothane," The Veterinary Record, vol. 149, no. 3, pp. 80-84, 2001.

[97] K. Kubo, T. Amari, T. Kaneki et al., "A 21-aminosteroid, U74006F, attenuates endotoxin-induced lung injury in awake sheep," Respirology, vol. 4, no. 2, pp. 167-172, 1999.

[98] C. D. Spence, A. Brown, J. P. Coghlan, D. G. Parkes, J. A. Whitworth, and B. A. Scoggins, "Rapid haemodynamic response to adrenocorticotrophin and the role of peripheral resistance in adrenocorticotrophin-induced hypertension in conscious sheep," Journal of Hypertension, vol. 7, no. 4, pp. 277-285, 1989.

[99] J. Bennett, "Regional body surface area of sheep," Journal of Agricultural Science, vol. 81, pp. 429-432, 1973.

[100] P. D. MacFarlane, N. Grint, and A. Dugdale, "Comparison of invasive and non-invasive blood pressure monitoring during clinical anaesthesia in dogs," Veterinary Research Communications, vol. 34, no. 3, pp. 217-227, 2010.

[101] R. Robinson and C. Seymour, "A potentially fatal complication of arterial cannulation caused by a faulty T-connector," Veterinary Anaesthesia and Analgesia, vol. 38, no. 3, pp. 274-275, 2011.

[102] H. L. Tan, M. Pinder, R. Parsons, B. Roberts, and P. V. van Heerden, "Clinical evaluation of USCOM ultrasonic cardiac output monitor in cardiac surgical patients in intensive care unit," British Journal of Anaesthesia, vol. 94, no. 3, pp. 287-291, 2005.

[103] S. Horster, H.-J. Stemmler, N. Strecker et al., "Cardiac output measurements in septic patients: comparing the accuracy of USCOM to PiCCO," Critical Care Research and Practice, vol. 2012, Article ID 270631, 5 pages, 2012.

[104] W. W. Muir and J. A. E. Hubbell, Handbook of Veterinary Anesthesia, Mosby, 1995. 
[105] N. S. Matthews, S. Hartke, and J. C. Allen Jr., "An evaluation of pulse oximeters in dogs, cats and horses," Veterinary Anaesthesia and Analgesia, vol. 30, no. 1, pp. 3-14, 2003.

[106] M. Marshall, "Capnography in dogs," Compendium on Continuing Education for the Practicing Veterinarian, vol. 26, no. 10, pp. 761-778, 2004.

[107] K. R. Dunster, M. Friese, J. F. Fraser, G. J. Cowin, and A. Schibler, "Ventilation distribution in rats: part I-the effect of gas composition as measured with electrical impedance tomography," Biomedical Engineering Online, vol. 11, no. 1, pp. 64-64, 2012.

[108] K. R. Dunster, M. E. J. Friese, J. F. Fraser, G. J. Galloway, G. J. Cowin, and A. Schibler, "Ventilation distribution in rats: part 2-a comparison of electrical impedance tomography and hyperpolarised helium magnetic resonance imaging," Biomedical Engineering Online, vol. 11, article 68, 2012.

[109] S. Dunlop, J. Hough, T. Riedel, J. F. Fraser, K. Dunster, and A. Schibler, "Electrical impedance tomography in extremely prematurely born infants and during high frequency oscillatory ventilation analyzed in the frequency domain," Physiological Measurement, vol. 27, no. 11, article 1151, 2006.

[110] C. A. Grant, J. F. Fraser, K. R. Dunster, and A. Schibler, "The assessment of regional lung mechanics with electrical impedance tomography: a pilot study during recruitment manoeuvres," Intensive Care Medicine, vol. 35, no. 1, pp. 166-170, 2009.

[111] D. Rooney, M. Friese, J. F. Fraser, K. R Dunster, and A. Schibler, "Gravity-dependent ventilation distribution in rats measured with electrical impedance tomography," Physiological Measurement, vol. 30, no. 10, pp. 1075-1085, 2009.

[112] C. Shi, S. Boehme, E. K. Hartmann, and K. Markstaller, "Novel technologies to detect atelectotrauma in the injured lung," Experimental Lung Research, vol. 37, no. 1, pp. 18-25, 2011.

[113] K. O. Möller, G. Nilsson, and B. Fagrell, "Laser-Doppler Flowmetry for microcirculation monitoring. Introduction," Technology and Health Care, vol. 7, no. 2-3, pp. i-ii, 1999.

[114] T. W. L. Scheeren, "Monitoring the microcirculation in the critically ill patient: reflectance spectroscopy," Intensive Care Medicine, vol. 37, no. 6, pp. 1045-1046, 2011.

[115] D. De Backer, K. Donadello, and D. O. Cortes, "Monitoring the microcirculation," Journal of Clinical Monitoring and Computing, vol. 26, no. 5, pp. 361-366, 2012.

[116] H. Qiu, Y. Zhou, Y. Gu et al., "Monitoring microcirculation changes in port wine stains during vascular targeted photodynamic therapy by laser speckle imaging," Photochemistry and Photobiology, vol. 88, no. 4, pp. 978-984, 2012.

[117] A. Bizzarri, H. Koehler, M. Cajlakovic et al., "Continuous oxygen monitoring in subcutaneous adipose tissue using microdialysis," Analytica Chimica Acta, vol. 573-574, pp. 48-56, 2006.

[118] "Microdialysis in tissue chemistry monitoring," Inpharma Weekly, vol. 1329, no. 1, p. 2, 2002.

[119] M. Theodorakopoulou, S. Orfanos, A. Diamantakis et al., "Tissue microdialysis in critically ill septic patients: associations with sepsis severity and mortality," Critical Care, vol. 14, supplement 1, p. P148, 2010.

[120] M. Theodorakopoulou, N. Nikitas, S. Orfanos et al., "Extracellular metabolic alterations in critically ill septic patients studied by adipose tissue microdialysis," Critical Care, vol. 14, supplement 2, p. P31, 2010.

[121] A. de la Peña, P. Liu, and H. Derendorf, "Microdialysis in peripheral tissues," Advanced Drug Delivery Reviews, vol. 45, no. 2-3, pp. 189-216, 2000.
[122] S. Chemonges-Nielsen, S. F. Sommerlad, and L. J. Filippich, "The effects of peripheral and central warming on body temperature during canine laparotomy," Australian Veterinary Practitioner, vol. 33, no. 2, pp. 50-56, 2003.

[123] C. Tan, M. Govendir, S. Zaki, Y. Miyake, P. Packiarajah, and R. Malik, "Evaluation of four warming procedures to minimise heat loss induced by anaesthesia and surgery in dogs," Australian Veterinary Journal, vol. 82, no. 1-2, pp. 65-68, 2004.

[124] G. Simonova, J. P. Tung, J. F. Fraser et al., "A comprehensive ovine model of blood transfusion," Vox Sanguinis, vol. 106, no. 2, pp. 153-160, 2014.

[125] J. P. Tung, Y. L. Fung, M. Nataatmadja et al., "A novel in vivo ovine model of transfusion-related acute lung injury (TRALI)," Vox Sanguinis, vol. 100, no. 2, pp. 219-230, 2011.

[126] M. Clare and K. Hopper, "Mechanical ventilation: ventilator settings, patient management, and nursing care," Compendium on Continuing Education for the Practicing Veterinarian, vol. 27, no. 4, pp. 256-269, 2005.

[127] I. Grossbach, L. Chlan, and M. F. Tracy, "Overview of mechanical ventilatory support and management of patient- and ventilator-related responses," Critical Care Nurse, vol. 31, no. 3, pp. 30-44, 2011.

[128] G. Gürsel and M. Aydoğdu, "Patient-ventilator interaction," Tüberküloz ve Toraks, vol. 57, no. 4, p. 453, 2009.

[129] D. R. Hess and B. T. Thompson, "Patient-ventilator dyssynchrony during lung protective ventilation: what's a clinician to do?" Critical Care Medicine, vol. 34, no. 1, pp. 231-233, 2006.

[130] E. Kondili, N. Xirouchaki, and D. Georgopoulos, "Modulation and treatment of patient-ventilator dyssynchrony," Current Opinion in Critical Care, vol. 13, no. 1, pp. 84-89, 2007.

[131] K. G. Mellott, M. J. Grap, C. L. Munro, C. N. Sessler, and P. A. Wetzel, "Patient-ventilator dyssynchrony clinical significance and implications for practice," Critical Care Nurse, vol. 29, no. 6, pp. 41-55, 2009.

[132] T. M. Corona and M. Aumann, "Ventilator waveform interpretation in mechanically ventilated small animals," Journal of Veterinary Emergency and Critical Care, vol. 21, no. 5, pp. 496514, 2011.

[133] M. Engström, P. Reinstrup, and U. Schött, "An in vitro evaluation of standard rotational thromboelastography in monitoring of effects of recombinant factor VIIa on coagulopathy induced by hydroxy ethyl starch," BMC Blood Disorders, vol. 5, article 3, 2005.

[134] K. A. Landskroner, N. C. Olson, and G. J. Jesmok, "Thromboelastography measurements of whole blood from factor VIIIdeficient mice supplemented with rFVIII," Haemophilia, vol. 11, no. 4, pp. 346-352, 2005.

[135] E. A. Silva, E. T. Leite, C. Teles et al., "Rotational thromboelastography in a patient with heparin-induced thrombocytopenia: a case report," Critical Care, vol. 11, supplement 3, p. P49, 2007.

[136] U. Kalina, H.-A. Stöhr, H. Bickhard et al., "Rotational thromboelastography for monitoring of fibrinogen concentrate therapy in fibrinogen deficiency," Blood Coagulation \& Fibrinolysis, vol. 19, no. 8, pp. 777-783, 2008.

[137] G. Bartfeld, M. Ellis, A. Lubetzky, V. Yahalom, and G. Kenet, "Storage of blood components does not decrease haemostatic potential: in vitro assessment of fresh versus stored blood components using thromboelastography," Transfusion Medicine and Hemotherapy, vol. 37, no. 6, pp. 329-335, 2010. 
[138] T. Tomori, D. Hupalo, K. Teranishi et al., "Evaluation of coagulation stages of hemorrhaged swine: comparison of thromboelastography and rotational elastometry," Blood Coagulation \& Fibrinolysis, vol. 21, no. 1, pp. 20-27, 2010.

[139] J. R. Yoo, S. Y. Kim, K. S. Kim, and S. J. Joo, “AS-025 prevalence and clinical characteristics of aspirin resistance defined by impedance platelet aggregometry," The American Journal of Cardiology, vol. 109, no. 7, supplement, p. S13, 2012.

[140] R. Xie, W. Cui, H. Zhang, F. Liu, J. Liu, and X. Yang, "AS-219: comparison of two assays in platelet aggregometry: whole blood impedance platelet aggregometry and turbidimetric platelet aggregometry," The American Journal of Cardiology, vol. 105, no. 9, p. 93A, 2010.

[141] D. Bolliger, M. D. Seeberger, K. A. Tanaka et al., "Pre-analytical effects of pneumatic tube transport on impedance platelet aggregometry," Platelets, vol. 20, no. 7, pp. 458-465, 2009.

[142] U. T. Seyfert, H. Haubelt, A. Vogt, and P. Hellstern, "Variables influencing Multiplate whole blood impedance platelet aggregometry and turbidimetric platelet aggregation in healthy individuals," Platelets, vol. 18, no. 3, pp. 199-206, 2007.

[143] A. Dyszkiewicz-Korpanty, H. Olteanu, E. P. Frenkel, and R. Sarode, "Clopidogrel anti-platelet effect: an evaluation by optical aggregometry, impedance aggregometry, and the Platelet Function Analyzer (PFA-100)," Platelets, vol. 18, no. 7, pp. 491496, 2007.

[144] S. Chemonges, J. P. Tung, and J. F. Fraser, "Proteogenomics of selective susceptibility to endotoxin using circulating acute phase biomarkers and bioassay development in sheep: a review," Proteome Science, vol. 12, article 12, 2014.

[145] S. Asmussen, D. M. Maybauer, J. F. Fraser et al., "Extracorporeal membrane oxygenation in burn and smoke inhalation injury," Burns, vol. 39, no. 3, pp. 429-435, 2013.

[146] J. Ross Jr., "Considerations regarding the technique for transseptal left heart catheterization," Circulation, vol. 34, no. 3, pp. 391399, 1966.

[147] A. Cheng and H. Calkins, "A conservative approach to performing transseptal punctures without the use of intracardiac echocardiography: stepwise approach with real-time video clips," Journal of Cardiovascular Electrophysiology, vol. 18, no. 6, pp. 686-689, 2007.

[148] K. Hahn, T. Bajwa, J. Sarnoski, D. H. Schmidt, and R. Gal, "Transseptal catheterization with transesophageal guidance in high risk patients," Echocardiography, vol. 14, no. 5, pp. 475-480, 1997.

[149] D. Hodeige, M. De Pauw, W. Eechaute, J. Weyne, and G. R. Heyndrickx, "On the validity of blood flow measurement using colored microspheres," American Journal of Physiology-Heart and Circulatory Physiology, vol. 276, no. 4, pp. H1150-H1158, 1999.

[150] P. J. Schenarts, H. G. Bone, L. D. Traber, and D. L. Traber, "Effect of severe smoke inhalation injury on systemic microvascular blood flow in sheep," Shock, vol. 6, no. 3, pp. 201-205, 1996.

[151] C. Trim, "Causes of severe complications and death during and after anesthesia," in Proceedings of the Atlantic Coast Veterinary Conference, 2010.

[152] T. Colville, "Monitoring anesthetized animals-how general anesthesia affects normal anatomy and physiology," in Proceedings of the Atlantic Coast Veterinary Conference, 2011.

[153] C. Ballard-Croft, D. Wang, L. R. Sumpter, X. Zhou, and J. B. Zwischenberger, "Large-animal models of acute respiratory distress syndrome," Annals of Thoracic Surgery, vol. 93, no. 4, pp. 1331-1339, 2012.
[154] C. Kilkenny, W. J. Browne, I. C. Cuthill, M. Emerson, and D. G. Altman, "Improving bioscience research reporting: the arrive guidelines for reporting animal research," PLoS Biology, vol. 8, no. 6, Article ID e1000412, 2010. 


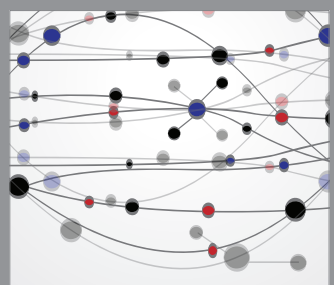

The Scientific World Journal
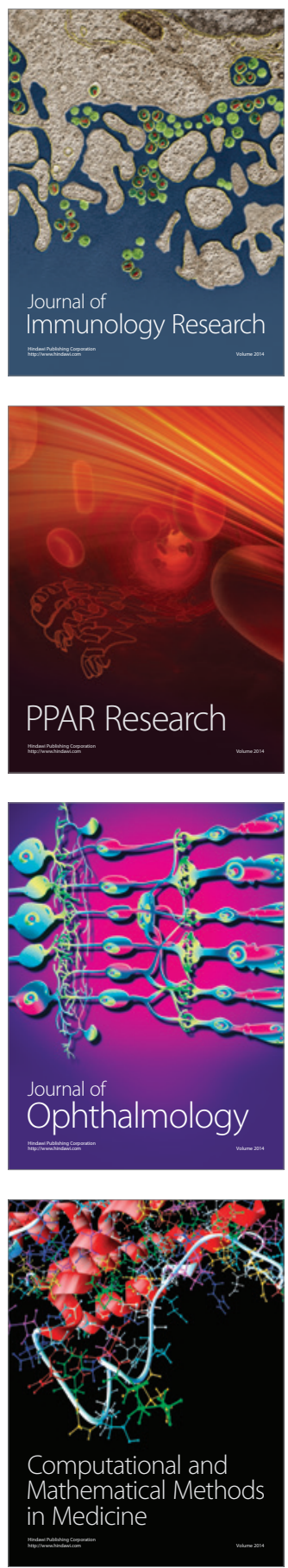

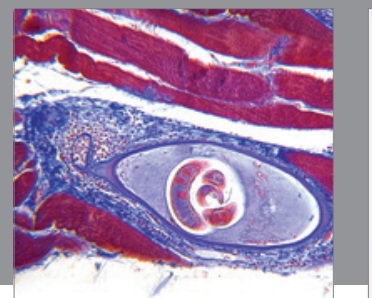

Gastroenterology

Research and Practice
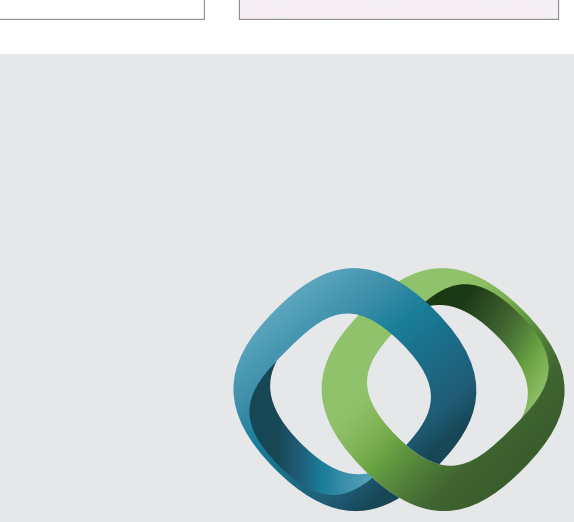

\section{Hindawi}

Submit your manuscripts at

http://www.hindawi.com
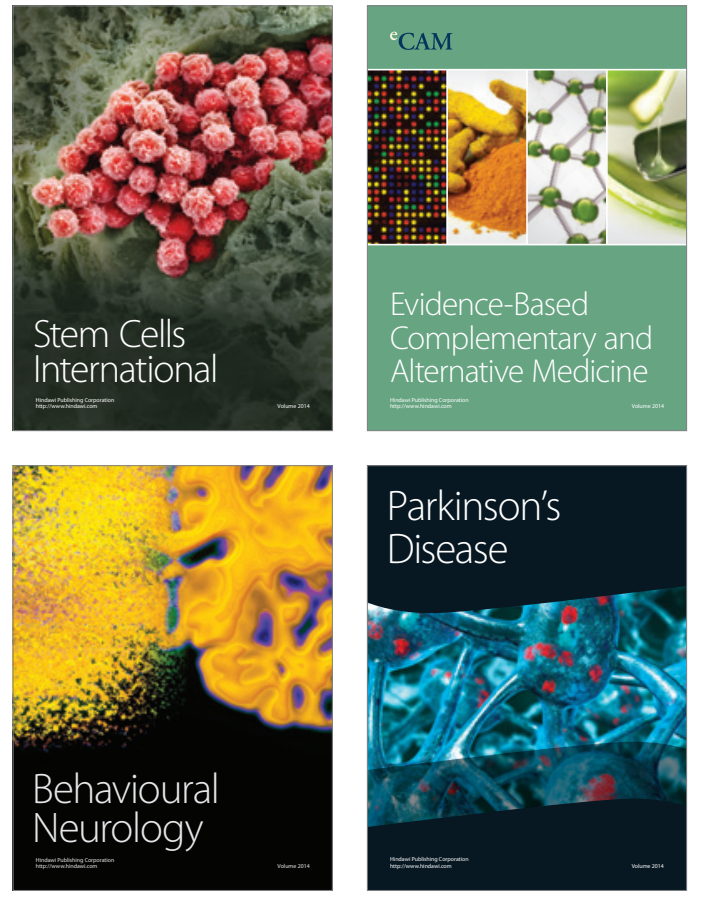
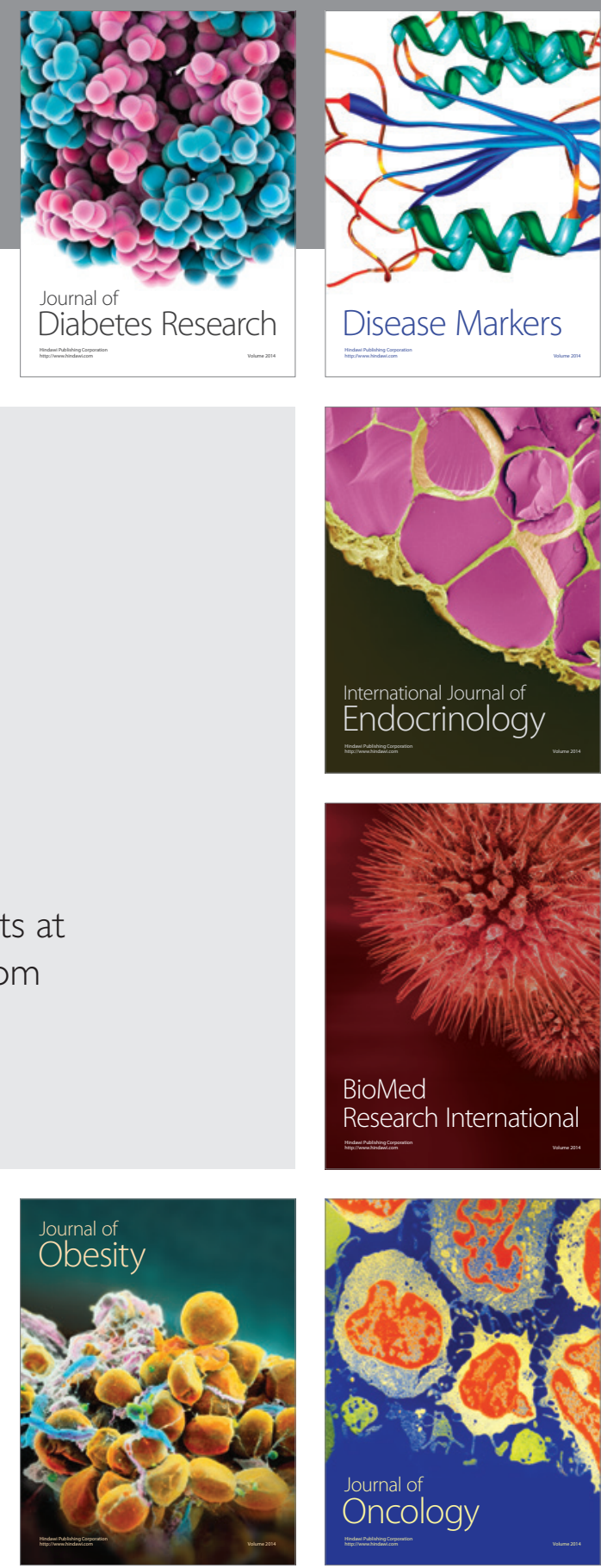

Disease Markers
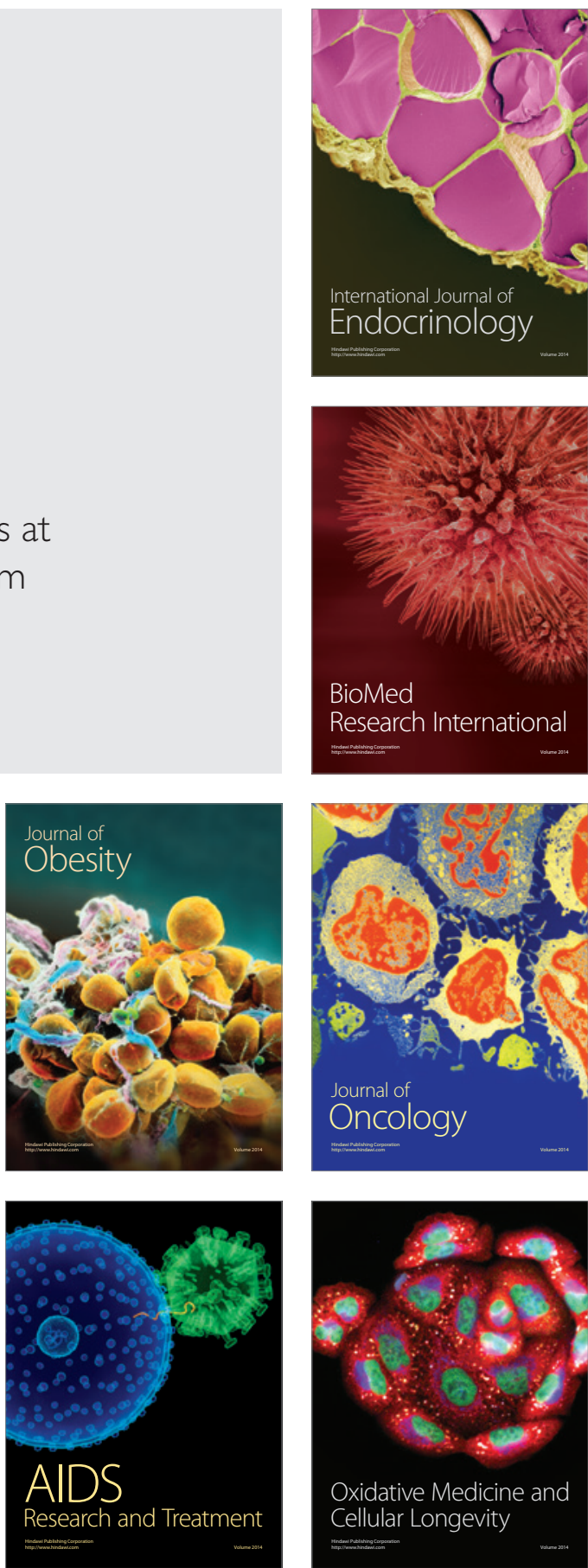